DOI: $10.20472 / E F C .2017 .008 .012$

JACK STRAUSS

University of Denver, United States

\title{
DO HIGH SPEED RAILWAYS LEAD TO URBAN ECONOMIC GROWTH IN CHINA?
}

\begin{abstract}
:
This paper investigates the impact of high-speed railroads (HSR) on city-level economic activity using a new dataset for approximately 200 cities in China from 2007-2014. We apply panel Granger causality methods to assess whether increases in a city's accessibility increases GDP growth, GDP per capita growth and wage growth. Or does causality run the opposite way - does rising economic growth boost accessibility? Results document that increases in accessibility lead to significant and relatively large increases in GDP growth on the city-level; further, the benefits substantially out-weigh HSR's fixed costs, depreciation and subsidies. Out-of-sample methods document the importance of increases in HSR in forecasting GDP growth. Monte Carlo simulations document the usefulness of OLS and out-of-sample tests in assessing panel Granger Causality tests.
\end{abstract}

\section{Keywords:}

China Infrastructure, Granger Causality, High Speed Railroads 


\section{Introduction}

This paper constructs a dataset that measures the impact of high speed railroads (HSR) on the economic growth of Chinese prefecture-level cities. Precise measurement of infrastructure's effect is critical to understanding its economic impact on a region. Researchers since Hansen (1959) have used accessibility to measure the improvement of the spatiotemporal effect of transport infrastructure (Garrison, 1960; Moriss et al,, 1979; Keeble et al, 1981; Murayama, 1994; Gutiérrez et al, 1996; Li and Shum, 2001; Sohn, 2006; Wang et al, 2009; Rong, 2014). Accessibility improves on simpler methods of railroad construction in kilometers or costs, and we follow Shi and Zhou (2013) that use a weighted mean travel time that integrates both time and fare. Our accessibility index accounts for time savings and travel expenditures for over 200 Chinese cities from 2007-2014. We apply panel Granger causality methods to assess whether increases in a city's accessibility raise growth in GDP, per capita GDP and wages. Or does causality run the opposite way - does rising economic growth increase accessibility?

The case for infrastructure spending for promoting economic activity, although well-cited in the literature, has received renewed attention for its high costs. The argument for increased HSR relies on the simple intuition that railroads connect consumers, businesses and ideas together. Before intercity competition can generate economic activity, there must be reliable physical market access; e.g., a generation ago, China consisted of dozens of isolated pockets of large cities with many millions of consumers, but with few easy transport connections between cities. Transportation infrastructure such as HSR increases the access of medium cities, large cities and megacities to each other, and due to agglomeration effects of cities, may lead capital and skilled labor to move to more productive regions. The MIT Urban Planning department states, "By collapsing travel times and increasing inter-urban accessibility, HSR networks have unparalleled capacity to reconfigure urban economic geography regionally and nationally" (Fang and Zhao, 2014). ${ }^{1}$ Moreover, China has for several decades experienced severe railway constraints due to outdated technology, growing population and rapidly growing economic growth; e.g., in 2009, China had less rail line per km/population than India and less than half the ratio of rail line per $\mathrm{km}$ of land area than India (Wu, 2013). By 2014, however, China had the largest HSR in the world accounting for $46 \%$ of the world's total, and the "network is introducing substantial improvement in accessibility" (Jaio et al, 2014).

\footnotetext{
${ }^{1}$ Chen and Silva (2014) posit that "It is commonly acknowledged that investment on transport infrastructure increases the accessibility to resources, goods and markets, and thus improves the competitiveness of a region (Gutiérrez, 2001; Levinson, 2012) and enhances economic integration (Blum, 1982; Rietveld, 1989). Reductions in travel time and travel cost can also give rise to productivity growth through reinforcing the agglomeration benefits (Venables, 2007; Graham, 2007; Hensher et al, 2012)."
} 
At the same time, $\mathrm{Wu}$ (2013) points out the financial performance of HSR has been more costly than anticipated, and the value of Chinese time still low by European standards. Bloomberg (Minter, 2016) reports that the state-owned China Railroad Corporation (2016) states its debt had growth $10.4 \%$ in 2015 and exceeds $\$ 600$ billion; a public debt greater than the total public debt of Greece, and two thirds of this debt is related to HSR construction. Hence, while there is a strong need for increasing railway capacity in China, HSR may be overly expensive and not generate the economic boom relative to its high costs. The economic impact of Chinese HSR is thus a highly relevant public policy topic, and our paper is the first to examine the economic benefits of HSR relative to their large fixed costs.

The paper's second contribution is methodological. Panel datasets have become common to analyze large-scale microeconomic panels, because they contain substantially more information than an aggregate time series as well as potentially avoid the spurious effects of unspecified time trends. Recent emphasis using dynamic panel methods, a setup relevant to Granger causality, has emphasized the time series problems with OLS and LSDV (least squares dummy variable or OLS with fixed effects). Both methods, but particularly LSDV, lead to significant and large bias in the lagged autoregressive term.

To mitigate the bias in dynamic panels, GMM methods such as Arrelano and Bond (1991) and Arellano and Bover (1995) have been introduced. GMM however suffers from several problems. First, the GMM solution of adding lagged differences to mitigate the bias leads to loss of observations, which can be important when the time series sample size is small. Second, the GMM estimates can be sensitive to the choice of instruments and their lag lengths. Third, GMM may suffer from standard error bias if the heteroskedasticity is not correctly modelled; although the White heteroskedasticity correction is often used, it assumes the errors are contemporaneously or cross-sectionally correlated. A panel correction method of Beck and Katz (1995) maybe more appropriate, or the heteroskedasticity could be of unknown forms, and correlated both across time and cross-sectionally. In this case, the appropriate weighting of the covariance matrix is problematic and heteroskedasticity will be hard to mitigate, implying the $t$ statistics will likely be biased. ${ }^{2}$ As a result, GMM may over-fit the data (due to selection of particular instruments in-sample or insufficient time series), and thus fail out-of-sample.

Our paper shows that OLS can be applied both in-sample and out-of-sample in a dynamic panel to test Granger Causality. Following Judson and Owen, we conduct Monte Carlo

\footnotetext{
${ }^{2}$ OLS will also suffer from this problem. Although many empirical studies now provide standard error estimates that are heteroscedasticity and autocorrelation consistent, cross-sectional or "spatial" dependence is still largely ignored (Hoechle, 2007)
} 
simulations to investigate the bias of the lagged " $X$ " (distributed lag) variable, as this is the variable of particular interest in Granger Causality. To tackle the potential biases in both parameter and standard errors, Monte Carlo also demonstrate the appropriateness of out-of-sample methods. Granger causality methods are essentially tests of predictive ability, not causality, and hence out-of-sample tests can evaluate whether an increase in accessibility predicts increases in GDP, or does GDP lead to boosts in accessibility.

Out-of-sample methods have three advantages over in-sample tests: (1) highlight potential problems with parameter stability and model break-down as well as model overfitting, and (2) highlight a bias-efficiency trade-off, which could highlight the advantages/disadvantages of OLS compared to GMM and (3) do not suffer from potential standard error problems. Parameter stability is particularly important in our context because of potential diminishing returns; infrastructure spending is likely to have large positive effects in the beginning as crucial cities are connected, but may suffer from declining marginal benefit as the year's progress, since more marginal cities may be connected to the network. GMM is further more likely to suffer from over-fitting or data-mining as the choice of instruments, their specific lag lengths and their exogeneity can be important in accurately forecasting. Second, if the OLS bias is low relative to the estimation error, an OLS framework should predict well out-of-sample relative to GMM due to increased efficiency. Third, both GMM and OLS standard errors, and thus inference maybe biased if the correction across the errors are not corrected. The out-of-sample $\mathrm{R}^{2}$ statistic, used for instance in stock market predictability, can be informative in measuring the amount of predictability a variable possesses.

According to Hansen (1959), accessibility is the potential of interaction and can be used to estimate spatiotemporal changes in urban areas. Research by the Chinese Academy of Sciences (Wang et al, 2009; Jiao et al, 2014) indicates that HSR have a strong spatiotemporal convergence effect on China. The improvement of accessibility, however, does not automatically bring corresponding social and economic improvement. On one hand, transport infrastructure under specific conditions in terms of economics and investment, which are called Banister conditions, can boost economic and social progress (Banister and Berechman, 2001). On the other hand, HSR, if it fails to meet social demands and its expenditures exceed opportunity costs, investment can lead to economic loss, excessive debt and consequently constrain or postpone the effect of economic growth (Wu and Nash, 2014; Zhao, 2015).

A preview of the results shows that increases in accessibility Granger Cause significant and relatively large increases in GDP growth on the city-level, boosting GDP growth by approximately $1 \%$ over three years. Results are robust to both GMM and OLS methods, and further highlight that increases in accessibility Granger cause increases in GDP growth per 
capita and wage growth. In contrast, increases in GDP growth, GDP growth per capita or wage growth do not lead to increases in accessibility. The presence of one-way Granger causality likely occurs because the top-down decision-making structure in China's HSR system supports the exogeneity assumption of cities' accessibility with respect to economy (Fang and Zhao, 2014). Lastly, investment in HSR boosts GDP growth greater than road construction.

Our Monte Carlo results demonstrate that OLS methods do not lead to a large bias in the lagged distributed variable, $\mathrm{X}_{\mathrm{t}-1}$, which is the variable of interest for Granger Causality. Simulation results highlight this bias is generally between 1-7\%. Monte Carlo simulations also investigate the relevance of Clark-West's adjustment of the mean square prediction error (MSPE), which is used in the Diebold Mariano test. Results reveal that the increase in the cross-section, similar to the increase in the time series, leads to critical values of a normal distribution. Hence, we can use OOS methods to evaluate panel Granger Causality tests.

Out-of-sample (OOS) results using OLS reveal that HSR significantly forecasts GDP growth. HSR leads to significant and substantial reductions in OOS MSPE. The OLS panel estimates further do not suffer from parameter instability or model over-fit, and hence recent increases in HSR continue to boost future GDP growth. ${ }^{3}$ Increases in accessibility explain approximately $8 \%$ out-of-sample GDP growth, an economically meaningful amount. In contrast, GDP growth does not substantially forecast future GDP growth, and the GDP estimates that generate the GDP forecasts tend to be relatively instable. GMM estimation does not significantly or substantially lower out-of-sample MSPE relative to OLS methods.

Overall, this paper's contribution involves constructing a large panel of Chinese HSR's time value and travel expenditures to study the spatiotemporal effect of HSR on the urban economic growth in China.

\section{Background and Literature Review}

\section{A. Chinese Railroad Construction}

Following the inauguration of the first HSR, Beijing-Tianjin Intercity Railway, on August 1, 2008, China's HSR by the end of 2015 has grown to $19000 \mathrm{~km}$ or $40 \%$ of the total transport volume of 2.5 billion passengers (China Railway Corp., 2016). HSR is defined as a rail system having maximum speeds of $250 \mathrm{KMPH}$ or more; in contrast, the average Chinese railroad has speeds of $50 \mathrm{KMPH}$. Figure IA shows that both rail operating mileage and HSR continues to rise, and

\footnotetext{
${ }^{3}$ Note further the estimated correlation between GDP and ACC across our 200 city panel is only $1 \%$, so the OLS or LSDV bias in estimating the autoregressive term is not likely to introduce bias in the distributed lag term.
} 
total rail road km exceeds $120,000 \mathrm{~km}$. From $2010-2015$, HSR grew by approximately $20 \%$ a year. Figure IB shows that the proportion of railroad passenger volume sharply rose in 2013-2014.

Figure IA

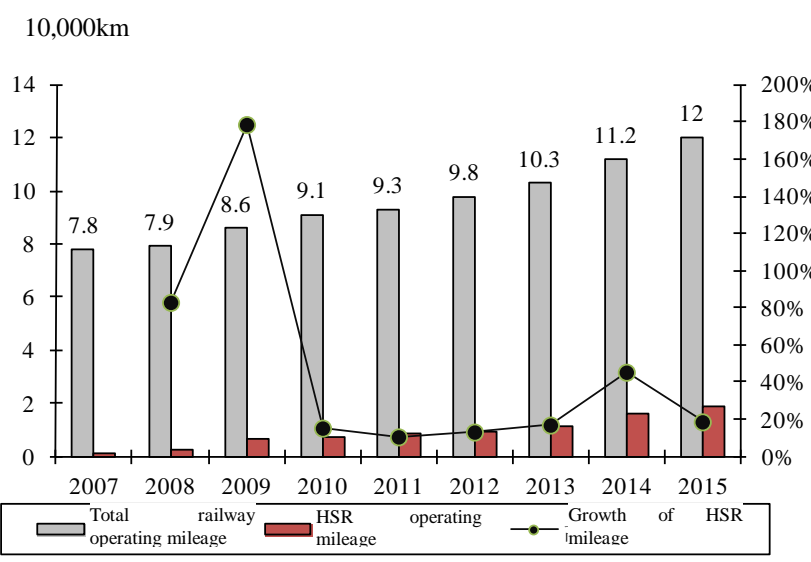

Figure IB

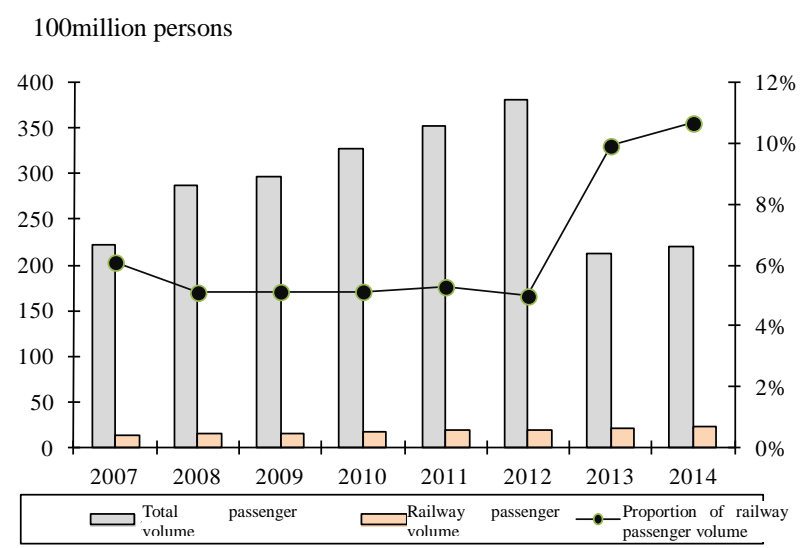

Figure $1 \mathrm{~A}$ HSR mileage in China

Figure 1B Proportion of Rail passenger volume in China

The World Bank (Ollivier, 2014) finds the number of HSR trains average 1,330 pairs a day, most cities of 500,000 are now connected to the HSR grid, and HSR links up the most vigorous economic development regions. As a result of passenger traffic growing $39 \%$ per annum, "China HSR lines carried slightly more HSR passenger-km (214 billion) than the rest of the world combined. This represented about 2.5 times the HSR passenger-km of Japan, the second largest country in terms of HSR traffic" (Ollivier, 2014). Hu (2009), Zhang (2012) and Ollivier et al (2014) maintain that Chinese HSR possess significant impacts on the regional economy, especially on tourism. In contrast, Zhao et al (2015) argue that HSR have a negative impact on China's economic growth and should be developed prudently.

\section{B. Literature Review}

The relation between transport and economic growth is a classic topic in economic geography. Since the social and economic effect of HSR is widely disputed in China and across the world (Wu, 2014; Zhao, 2015), the impact of HSR on urban economic growth is a topic valuable for in-depth study. The mechanism of HSR effect on urban growth is studied mainly from three aspects: first, the change in accessibility and spatiotemporal compressibility effect caused by HSR based on the theory and method of geographic economy (Wang and Rong, 2014); second, the study of HSR for releasing railway capacity, promoting effective circulation of factor resources and urban agglomeration economies (Rong, 2014); and third, analysis and criticism 
on the negative effects of HSR (Sasaki et al, 1997; Zhao, 2015). Zhou (2010) believes HSR along major transport channels in China greatly improve the effective supply of railway transport capacity and create favorable conditions for the harmonized development of regional economy and sustainable development.

Construction of HSR essentially supports inter-regional cooperation and development. Wang (2010) believes construction and development of HSR serve as an important link in Chinese economic development, and HSR is remarkably low carbon and energy saving. HSR development enables an urban agglomeration effect and fosters harmonized development between regions and urban-rural areas. HSR facilitates the development of knowledge-based economy and its influence spreads from urban to neighboring areas, thus HSR pivots are particularly important (Chen and Hall, 2012). HSR expedites circulation of factors and resources, expands market coverage, builds up regional economic integration, and establishes factor circulation and allocation mechanism for narrowing regional gaps. The mechanism includes promoting the development of modern service industry such as tourism, thus more job opportunities are created and exploitation of human capital is enhanced (Zhang, 2011).

HSR effect on urban growth includes factory site selection, industry, employment, population and effects on cities and city clusters in different time and spatial dimensions (Willigers and van Wee, 2011). Zhang and Nie (2010) explain China's integrated development of regional economy through urban agglomeration effect and integration effect, i.e. HSR shortens the spatiotemporal distance caused by externality and facilitates spatial restructuring of industry, employment, population, residence and towns within city clusters; meanwhile, HSR development may further stimulate trans-regional circulation of production factors, improve effective spatial distribution of resources, foster transport integration, and promote economic integration. Analysis on HSR effect on cities must take into account such factors as relation between cities, spatial effect and the effect of HSR stations (Garmendia et al, 2012). Ortega (2012) believes that HSR networks link up powerful economic centers and improved accessibility will amplify regional agglomeration.

Previous studies on the relation between HSR and urban development stress the necessity of multi-level analysis and reveal that HSR effect differs between small cities and medium to large cities; e.g., research in Spain and France implies that HSR effect is more significant in medium and large cities, mainly because HSR improves urban accessibility and creates more development areas (Ureña, et al, 2009). Chen and Silva (2014) use a panel structure formula model to analyze the effect of HSR network on provincial economies, specifically on employment and economic growth, between 1990 and 2010 in Spain, with educational degree serving as an exogenous variable. The empirical result indicates that, endogenously, transport 
investment in a province is co-related to its economic development, i.e. investment in HSR has positive effect on economic growth and employment rate of the province (Vickermann, 1997; Banister and Berechman, 2000). Sasaki et al (1997) holds that the Shinkansen has limited effect on regional expansion; further, economic activities are concentrated in large cities such as Tokyo and Osaka, and small cities may become victims of HSR where resources for development are more likely to be diverted to neighboring large cities via HSR. One the other hand, convenient HSR allows small towns to become independent from neighboring cities and directly access to large cities sitting far away.

According to Banister and Berechman (2001), in developed countries where transport networks boast satisfactory accessibility, economic growth does not directly come from more investment in transport infrastructures, but requires coordination of economic externality, investment and political factors. Considering that China is a developing country, HSR investment may boost economic growth via multiplier effects and interact with economic conditions and policy mechanism constraints. Further, increased accessibility, by encouraging travel and trade, could boost coordination and cooperation; in this case, HSR construction not only directly stimulates economic growth, but also liberates the existing passenger and cargo transport capacity and saves travel time, which further enhances the urban economy in China.

\section{Data and Modelling}

\section{A. Data}

Data on standard railway and HSR come from Time Schedule of Passenger Train in China, and data on the 226 cities at prefecture-level and above are from China Urban Statistics Yearbook from 2007 to 2014. Due to some missing data, the panel consists of 201 cities. The actual sample represents more than 34 Trillion Yuan in 2014, or 53\% of total Chinese GDP, and hence is a relatively comprehensive sample of the Chinese economy.

Our two three dependent variables are:

GGDP $_{\mathrm{it}}$ : $\log$ growth rate of city $i$, at time $t$.

GGDPC $_{\text {it: }}$ per capita log growth rate of cities

$\mathbf{G W}_{\text {it: }}$ log growth rate of the wage rate of the city.

We are primarily interested in how rail investment affects accessibility, ACC, defined as:

$\mathbf{A C C}_{\mathrm{i}, \mathrm{t}}$ : the accessibility indicator and its construction is detailed in the appendix. 
IS $S_{i t}$ : urban industrial structure (unit: \%). This control variable measures the degree of urban development, and represented by the ratio between the added values of tertiary and secondary industries. The larger the value of the indicator, the higher the percentage of the tertiary industry in the city, the greater the industrial structure, and the more likely urban agglomeration effects occur.

\section{B. Model}

Panel data estimation possesses the advantage of increased power when the cross section is large, and the time series is small. Relative to time series, further, a panel data set typically has considerably heterogeneity across the cross-section, and does not suffer from spurious time trends (or aggregate) effects or unproxied aggregate effects such as business cycles, particularly if the estimation is demeaned. Relative to a cross-section sample, a panel dataset also has substantially more observations, allows for causality examination, and thus has often been used to analyze economic growth. In our case, for instance, does an increase in HSR accessibility lead to subsequent economic growth in a city? Consider the following Granger Causality setup:

(1) $Y_{i t}=\alpha_{1}+\rho_{1} Y_{i t-1}+\beta_{1} X_{i t-1}+\varepsilon_{i t}$

(2) $X_{i t}=\alpha_{2}+\rho_{2} X_{i t-1}+\beta_{2} Y_{i t-1}+\omega_{i t}$,

where $i$ is the cross section of $\mathrm{N}$ units and $\mathrm{t}=1 \ldots \mathrm{T}$ time periods. ${ }^{4}$ If $\beta_{1}>0$, then $\mathrm{X}_{\mathrm{it}-1}$ (lagged ACC) boosts GDP growth ( $\left.Y_{i t}\right)$; if $\beta_{2}>0$, then $Y_{i t-1}$ (lagged GDP growth) boosts ACC ( $\left.X_{i t}\right)$. The introduction however of dynamic endogenous variables introduces estimation problems, because the parameters estimates are biased in panel models with fixed effects and lagged dependent variables called the Nickell effect.

Nickell (1981) has demonstrated the LSDV (Least Squares Dummy Variable, or fixed effects) in a panel model leads to bias and is inconsistent, since $\mathrm{E}\left(\mathrm{Y}_{\left.\mathrm{it}-1, \varepsilon_{\mathrm{it}}\right)}\right.$ does not equal zero. Consider the error structure: $\varepsilon_{i t}=v_{i}+n_{i t}$. There is a simultaneity problem as the lagged dependent variable $\mathrm{Y}_{\mathrm{it}-1}$ is correlated with $\varepsilon_{\mathrm{it}}$ due to its correlation with the time-invariance component $v_{i}$. Nickell showed the inconsistency of $\rho$ as $N$ approaches infinity is order $1 / T$, which may be quite sizable in a "small $T$ " context. This occurs because $\mathrm{Y}_{\mathrm{t}-1}$ and $\varepsilon_{\mathrm{it}}-\varepsilon_{\mathrm{t}}$ are correlated. If $\rho>0$, the bias is negative and the persistence of $Y$ will be underestimated. Andersen and Hsiao (1981) and Hsiao (1986) both provide extensive discussions of this autoregressive bias. One solution to this error components problem is to remove the fixed effect in (1)-(2) by demeaning each cross section:

(3) $Y_{i t}-Y_{t}=\alpha_{1-} \alpha+\rho_{1}\left(Y_{i, t-1}-Y_{t-1}\right)+\beta_{1}\left(X i, t-1-X_{t-1}\right)+\varepsilon_{i t}-\varepsilon_{t}$,

(4) $Y_{\mathrm{it}}=\alpha_{1+} \beta_{1} X_{\mathrm{it}-1}+\rho_{1} Y_{\mathrm{it}-1}+\varepsilon_{\mathrm{it}}$,

where $Y_{t}$ and $X_{t}$ are summed across the time dimension for each city, and the italics denotes differenced. The demeaning operation creates a regressor which cannot be distributed

${ }^{4}$ To simplify the notation, we use a one time period lag; in our implementation, we use AIC lag lengths to determine the appropriate lag lengths. 
independently of the error term. The within-transformation however is unbiased and consistent if the explanatory variables are exogenous; however, in a causality setting this assumption is what the econometrician is testing so the exogeneity assumption cannot be imposed.

A solution to this problem involves taking first differences of the original model following Anderson and Hsiao (1981). The transformation removes both the constant term and the individual effect. Note, there is still correlation between $\mathrm{Y}_{\mathrm{it}-1}$ and the disturbance term (which is not a first-order moving average, MA(1)), since the former contains $\mathrm{Y}_{\mathrm{it}-1}$ and the latter contains $\varepsilon_{\text {it-1. }}$. However, with the individual effects removed, a straightforward instrumental variables estimator can be applied. We can construct instruments for the lagged dependent variable from the second and third lags of $Y_{i}$ in the form of differences or lagged levels. If $\varepsilon$ is i.i.d., these instruments will be highly correlated with the lagged dependent variable (and its difference) but uncorrelated with the composite error process. If $\varepsilon$ follows an AR(1), we can still employ this approach, but use the third and fourth lags of $Y_{i}$ and use GMM (see Arrelano and Bond, 1991). The problem is that when $\mathrm{N}$ is large and $\mathrm{T}$ is small, lagged differences lead to substantial loss of observations.

\section{Monte Carlo}

Our estimation not only follows the literature by employing GMM, but also applies OLS for several reasons. Although OLS will be bias, it will be more efficient since it possesses considerably more observations. In our case, GMM loses two observations due to the addition of lagged differences of the Arrelano/Bond procedure, and the sample has approximately 600 observations (three years times 201 cities); in contrast, the OLS sample will have five years and hence 1005 observations (2010-2014). The bias-efficiency trade-off could favor OLS if its bias is not large.

Simulation results by Judson and Owen (1999) show the bias of $\beta$ is substantially less severe than the bias of $\rho$. For instance, for $\mathrm{T}=5, \mathrm{~N}=100$, the bias for $\beta=.2(.8)$ is $-.098(-.005)$ for OLS and $.006(-.027)$ for LSDV. In contrast, the bias for $\rho=.2(.8)$ is $.225(.049)$ for OLS and -.147 (-.504) for LSDV. Hence, when the autoregressive term is large and there are fixed effects, the bias for the autoregressive term, $\rho$, is large; in contrast, the bias of the lagged distributed lag term, $\beta$, is relatively modest. Kiviet (2005) also shows the bias of $\beta$ is substantially less than the bias of $\rho$; however, his simulations are not for large N. In our sample, estimation results highlight a relatively small autoregressive term $\left(\rho_{1} \approx .2\right)$ and a larger lagged distributed lag term; hence, the $\beta$ 's bias for OLS and LSDV should be relatively small.

Our Monte Carlo Simulations for a $\mathrm{T}=5, \mathrm{~N}=200$, approximately our sample size, reveal a LSDV (OLS) bias for $\beta$ of $1.4 \%$ (7.5\%). Since we are testing Granger causality (and the effect of ACC on economic growth such as GDP), we are more interested in evaluating the significance and magnitude of the lagged $\beta$ term than the lagged $\rho$ terms. To further highlight the advantage of OLS we conduct out-of-sample forecasting and compare them to GMM; if the OLS bias is not very large, then OLS should yield lower MSPE.

We follow Kiviet (2005) in the setup; however we assume a correlation of .25 between $\rho$ and $\beta$ (due to relatively low estimated correlation in our panel) and assume values of .2 .5 and .8 for 
both $\rho$ and $\beta .^{5}$ Monte Carlo simulations reveal several interesting results. For our sample of $\mathrm{T}=5, \mathrm{~N}=200$, the top panel $(\rho=.2, \beta=.8$ ), OLS methods generate $\rho=.57$ and $\beta=.74$ and hence a large bias for the lagged autoregressive term $\rho$, but a modest bias for the lagged distributed lag term, $\beta$. The LSDV generates $\rho=.05$ and $\beta=.79$; this implies a very large autoregressive bias (Nickell effect), but a small distributed lag bias of approximately $1 \%$. Consider the bottom panel $(\rho=.5, \beta=.5)$. OLS generates $\rho=.67$ and $\beta=.44$ while LSDV generates $\rho=.25$ and $\beta=.50$. LSDV's bias is less than $1 \%$. Hence, inference concerning Granger causality that tests the effects of lagged X can be conducted using OLS and particularly LSDV methods.

\section{Alternative Specifications}

If there are simultaneous aggregate effects across the panel (for instance, contemporaneous large increases in ACC across the country and/or large increases in economy-wide GDP), an alternative procedure involves subtracting aggregate effects from each variable. Instead of summing each cross-section along the time-dimension (to remove the fixed effect like the procedure described above), this procedure subtracts the average GDP, ACC and IS across the panel. The equation then evaluates whether differences in ACC compared to the average ACC lead to changes in GDP different than average GDP across the economy.

Panel datasets typically possess heteroskedasticity across the panel. We use both White and panel-corrected heteroskedasticity procedure to mitigate the cross-section correlations. The White cross-section method assumes that the errors are contemporaneously or period clustered. This pooled regression is a multivariate regression (with an equation for each cross-section), and estimates robust standard errors for the system of equations. This method accommodates arbitrary heteroskedasticity and within cross-section correlation. Beck and Katz (1995) develop a variant or extension called Panel Corrected Standard Error (PCSE) methodology, which is robust to unrestricted unconditional variance matrices, but place additional restrictions on the conditional variance matrices. We use their cross-section method that handles cross-section correlation.

\section{Econometric Results}

\section{A. In-sample Analysis}

Tables 2 and 3 present GMM and OLS estimates for Granger Causality between GDP Growth (GGDP) and ACC, respectively. The top panel examines whether ACC Granger causes GGDP and the bottom panel examines reverse causality and whether past GDP growth leads to changes in ACC. Column (1) and (2) uses GMM estimates using lagged differenced data (as in Arellano and Bond, 1991), and lagged Orthogonal Deviations (Arellano and Bover, 1995), an alternative method of removing the individual effects. Both use the AB-n step, which uses residuals from the first step. Column (3) uses the AB 1-step and PCSE to assess the robustness of a different specification. Column 4 tests an additional alternative specification and subtracts aggregate effects as well as uses differenced $\mathrm{ACC},\left(\triangle \mathrm{ACC}_{\mathrm{it}}-\Delta \mathrm{ACC}_{\mathrm{At}}\right)$ where $\mathrm{A}$

\footnotetext{
${ }^{5}$ The estimated correlation, as mentioned earlier, is less than $2 \%$; hence, .2 is a conservative value; Monte Carlo simulations for larger correlation estimates such as .5 reveal relatively similar estimates as they only change the estimate of $\square$ by $1-5 \%$.
} 
denotes the aggregate effect (sums across N). Both AIC and SIC criteria determine three lag lengths, and hence we estimate the following VAR:

(5) $\operatorname{GGDP}=\rho_{1} \mathrm{GGDP}_{\mathrm{t}-1}+\rho_{2} \mathrm{GGDP}_{\mathrm{t}-2}+\rho_{3} \mathrm{GGDP}_{\mathrm{t}-3}+\beta_{1} \mathrm{ACC}_{\mathrm{t}-1}+\beta_{2} \mathrm{ACC}_{\mathrm{t}-2}+\beta_{3} \mathrm{ACC}_{\mathrm{t}-3}+\gamma_{1} \mathrm{IS}_{\mathrm{t}-1}+\gamma_{2} \mathrm{IS}_{\mathrm{t}-2}+\gamma_{3} \mathrm{IS}_{\mathrm{t}-3}$.

(6) $\mathrm{ACC}=\rho_{12} \mathrm{ACC}_{\mathrm{t}-1}+\rho_{22} \mathrm{ACC}_{\mathrm{t}-2}+\rho_{32} \mathrm{ACC}_{\mathrm{t}-3}+\beta_{12} \mathrm{GGDP}_{\mathrm{t}-1}+\beta_{22} \mathrm{GGDP}_{\mathrm{t}-2}+\beta_{32} \mathrm{GGDP}_{\mathrm{t}-3}+\gamma_{12} \mathrm{IS}_{\mathrm{t}-1}+\gamma_{22} \mathrm{IS}_{\mathrm{t}-2}+\gamma_{32} \mathrm{IS}_{\mathrm{t}-3}$.

Results for all four specifications demonstrate that past increases in ACC lead to relatively large increases in GDP of approximate $1 \%$, as $\beta_{1}+\beta_{1}+\beta_{3}=1.16,1.14,1.04$ for columns (1)-(3). In all first four specifications, the effect takes several years, as the coefficient for ACC in year $t$, $\beta_{3}$, is significant and larger than $\beta_{1}$ or $\beta_{2}{ }^{6}$ The last column shows that percentages changes in ACC different than the aggregate lead to .54 changes in GDP growth above the national average. The control variables, industrial structure, are often significant. Panel B evaluates the reverse causation specified in (6). The coefficient estimates for GDP are negative and significant, and suggests that poorly performing regions attract railroad investment. No specification supports the hypothesis that economic activity leads to higher HSR; hence, there is one-way causation from increases in HSR in a city to approximately $1 \%$ GDP growth over the next several years.

Table 3 presents OLS specifications. The first two columns demean (to remove fixed effects), but use alternative methods of accommodating for heteroskedasticity, White period (to control for arbitrary period correlation structures that occurs for large N, small T), and PCSE (that account for deviations in spherical errors). Column (3) uses a fixed effects model (LSDV), while column (4) also uses an LSDV model, but also (similar to Table 2) removes both aggregate effects and tests independent variable (ACC) in differenced growth rates.

OLS results in Panel A of Table 3 strongly support the GMM estimates in the prior table. Increases in ACC lead to significant and large increases in GDP, and again the GDP boosts occur in years 2 and 3 , and $\beta_{1}+\beta_{1}+\beta_{3}=1.09$ for Columns (1)-(2) and $\beta_{1}+\beta_{1}+\beta_{3}=.90$ for Column (3). The demeaned equation, similar to the GMM specification, shows that growth rates in ACC above the national average lead to GDP growth $\beta_{1}+\beta_{1}+\beta_{3}=.85$. F statistics for all eight specifications in Panel A, Tables 2 and 3 significantly reject at the $1 \%$ level: $\beta_{1}+\beta_{1}+\beta_{3}>0$. Note further the estimated correlation between GDP and ACC across the panel is only $1 \%$, so the OLS or LSDV bias in estimating the autoregressive term is not likely to introduce bias in the distributed lag term.

Estimates for GDP effects on ACC in Panel B are relatively small, but further confirm the conclusions from the GMM estimates in the prior table - cities with poorly performing GDP attract railroad investment. Cities with high GDP growth do not lead to/cause boosts in accessibility. Tables 4 and 5 demonstrate a similar relationship with per capita GDP growth. Overall, there is clear evidence that increases in railroads lead to increases in GDP growth (or per capita GDP growth), and not vice versa - increases in GDP growth do not lead to more railroad investment.

Results in Table 6 and 7 present GMM and OLS Granger causality results between wage

${ }^{6}$ Chen and Silva's (2014) specification for Spain show the temporal effects can take up to five years. 
growth and ACC. For both differenced and orthogonal GMM, the ACC estimates in year 2 particularly are large, significant and positive. Changing ACC to growth rates however changes the lag lengths as they are significant in year three and year one. OLS specifications also demonstrate that ACC leads to large, positive changes in wage growth; again, the effects take several years to occur.

\section{B. Out-of-Sample Analysis}

Since the literature has discussed the potential biases of OLS in dynamic lagged panels, we perform an out-of-sample (OOS) analysis to assess the predictive ability of ACC. OOS method further mitigate over-fitting and address parameter instability. If $\beta$ is instable, suffers from bias or its standard errors are biased (due to incorrectly mitigating heteroskedasticity), changes in ACC might not significantly predict innovations in GDP growth.

Table 8 investigates whether changes in ACC improve OLS forecasts of GDP growth and GDP growth per capita; measured OOS by RMSPE, which measures how far the mean of the prediction is from the mean of the actual series. RMSPE (also known as RMSE, root mean squared error or RMSFE, root mean squared forecast error) is the most frequent OOS metric and is the square-root of the sum of the prediction errors squared divided by the number of observations; the other three measures are given for robustness. The mean absolute error (MAE) is a relatively similar metric, but does not penalize large forecast errors as much, since it takes the absolute value instead of squaring the errors. Theil U2 will take values less than one when it is beating the naïve forecast, and the bias presents the amount the errors are biased.

Consider the RMSPE for the benchmark for growth in GDP and GDP per capita. Introducing equation (5) above reduces the RMSPE for 2013-2014 from .172 to .150 (or .22), a decline of $13 \%$. This is equivalent to an out-of-sample $\mathrm{R}^{2}$ oos of $13 \%$ as this is defined as 1 minus the sum of squared residuals of the forecast model divided by the sum of squared residuals of the benchmark model, which is the constant (for a discussion, see Campbell and Thompson, 2008, or Rapach, Strauss and Zhou, 2010). The next three rows contain restrictions that exclude GDP $\left(\rho_{\mathrm{t}-\mathrm{i}}=0\right)$, ACC $\left(\beta_{\mathrm{t}-\mathrm{i}}=0\right)$, and both ACC and GDP $\left(\rho_{\mathrm{t}-\mathrm{i}}=\beta_{\mathrm{t}-\mathrm{i}}=0\right) ;$ RMSPE respectively are: $.157, .144$ and .156. Including ACC to the model with IS lowers the RMSPE (MAE, Theil) from $.156(.112, .867)$ to $.144(.097, .738)$, which is a decline of $7.7 \%$ (and thus $\mathrm{R}^{2}$ oos =7.7\%). Further, excluding ACC from the full model increases the RMSE (MAE, Theil) from $.150(.109, .802)$ to $.157(.123, .868)$. Using the Clark-West statistic, both changes are significant at the $1 \%$ level, as the t-statistics are well above four. The model with both IS and ACC has an $\mathrm{R}^{2} \mathrm{OOS}=16 \%$; this represents relatively good OOS forecasts of GDP growth, as GDP growth is typically difficult to forecast out-of-sample. Moreover, adding GDP to the model with IS increases the model's RMSPE (MAE, Theil) from .151 $(.112, .867)$ to .157 $(.123, .868)$, and excluding GDP from the model improves the forecasting model. This means past GDP cannot help forecast OOS GDP, which is likely due to the estimated bias of $\rho$. Results in the bottom panel represent 2014, and demonstrate the robustness of the results.

Out-of-sample results are robust for GDP per capita; e.g., inclusion of ACC beyond IS leads to a substantial and significant decline RMSPE from .157 to .144 ; the $\mathrm{R}^{2}{ }_{\mathrm{OOS}}=18.6 \%$ and the Clark-West statistic has a $\mathrm{t}$ statistic of 4.5 (with problem less than .1\%). Again, the 
out-of-sample variance using OLS explains an economically meaningful amount of the variance of GDP per capita. Further, excluding ACC from the full model raises considerably RMSE from .159 to .166, and again is significant at the $1 \%$ level. Adding lagged GDP growth per capita (similar to adding GDP growth) leads to higher (not lower) RMSPE, and is likely driven by the bias of the $\rho$ estimate (which we discuss and demonstrate below). Lastly, ACC and IS each contribute approximately half the $\mathrm{R}^{2} \mathrm{oos}$ in both time periods and specifications; thus, increases in ACC explain (or forecast) about 8\% of GDP and GDP per capita growth out-of-sample.

Table 8 additionally presents GMM estimates to assess whether GMM OOS out-performs OLS. Results for the full model with IS, ACC and GDP have relative large RMSPE and MAE as the forecast errors are worse than the benchmark for both GDP and GDP per capita growth. The RMSPE is particularly large in Panel A. Hence, GMM fails to accurately forecast OOS. One reason is that OLS may more accurately estimate the parameters of ACC. To investigate this premise, the next row estimates the equation using GMM for GDP and IS, but estimates ACC using OLS. Although this is a slightly unusual specification, it takes advantage of each model's strength (GMM for estimating $\rho$ and OLS for estimating $\beta$ ) and to highlight the source of the GMM estimation problem. This specification significantly lowers the RMSPE and MAE compared to the GMM specification, and thus supports the proposition above that OLS produces more accurate estimates of $\beta$. Hence, the distributed lag variable, ACC, significantly forecasts growth GDP and GDP per capita more accurate when OLS is used; in contrast, GMM does not produce accurate OOS forecasts.

The inclusion of ACC estimated by OLS show above shows that RMSE declines and hence the model's forecast OOS are more accurate; however, it did not reveal the estimated signs or magnitude of $\beta$, which is important for policy analysis. Results in Table 3 reveal approximately that the sum of the $\beta$ approximately equal 1\%. The OLS $\beta$ estimate for 2010-2012 is .79 in Panel A, and for 2013-14=.91 in Panel B; the relatively similar estimates support parameter stability. In contrast, GMM produces instable estimates. The GMM estimates for $\rho$ changed substantially between Panel A and B, and are also considerably different that the results in column 1 of Tables 2 and 4 . The $\beta$ estimates are particularly instable, particularly for $\beta_{1}$, which is a large negative for several of the specifications. The failure of GMM out-of-sample maybe driven by over-fitting and/or a smaller sample size as it loses 402 observations ( $2 \mathrm{x}$ 201).

\section{Benefits versus Costs.}

Accessibility improvement and its contribution to economic growth alone cannot solely justify the huge investment of high speed railway infrastructure in China. The accessibility costs include the travel savings and ticket costs to the consumer, but did not include government expenditure on investment, depreciation nor any overall subsidy or loss. These are available according to China Railway Corporation (CRC) only on the aggregate level, not by city (and hence are not used in the ACC calculations). However, the total external benefit of HSR on economic growth should at least cover railway incremental costs of operational losses, depreciation and forgone opportunity cost due to sunk cost incurred by CRC. Railway incremental total costs (ITR) of high speed railway (HSR) in time t can be expressed as: 


$$
\mathrm{ITC}_{\mathrm{HSRt}}=\mathrm{OL}_{\mathrm{HSR}}+\mathrm{DC}_{\mathrm{HSRt}}+\mathrm{OC}_{\mathrm{HSR}},
$$

where OLHSRt are the operational losses attributed to high speed railways in year t. DC $\mathrm{HSRt}_{\text {is }}$ the depreciation cost of high speed railway investment. ${ }^{7} \mathrm{OC}_{\mathrm{HSR}}$ is the implicit cost or the opportunity cost forgone by allocating huge amount of investment in HSR rather than other more profitable channels. Note the operational losses, or subsidy, given in Table 9, are relatively low; hence, pricing of HSR covers most of the operating costs. ${ }^{8}$ According to the Chinese Railroad Corporation (2015), the weighted comprehensive depreciation ratio for railway infrastructure and facilities is $2.5 \%$. This estimate is a relatively high rate (and may exaggerate high speed railway depreciation ratio), since high speed railway lines have a comparatively longer life time than rolling stocks, communication, signaling and other fixed capitals. $\mathrm{OC}_{\mathrm{HSRt}}$ can be written as:

$\mathrm{OC}_{\mathrm{HSR}}=\mathrm{I}_{\mathrm{HSRt}} \times \mathrm{DR}_{\mathrm{t}}$,

where $\mathrm{I}_{\mathrm{HSR}}$ is the annual investment on HSR, and DR is the discount rate reflecting the time value of certain investment. The usual practice for railway transit is to adopt the Treasury bond rate as the discount rate. In recent years, $3.21 \%$ is used as the base discount rate for incentive mechanism design in PPP project (Bian, 2016).

CRC statistics show that HSR comprise nearly $70 \%$ of railway investment in the 12 th five year plan (2011-2015). This means we estimate incremental total cost of HSR by multiplying railway industry's total incremental cost of year $t$ with $\gamma(.7)$, the proportion of HSR/overall railway cost. In 2016, the National Development and Reform Commission conducted a research on railway sustainability ( $\mathrm{Wu}$ and $\mathrm{Li}, 2016)$. The estimated ITC $_{\mathrm{HSR}}$ in Table 9 show the costs are approximately 20-33 billion Yuan annually over the past five years (2010-2014). Our research shows that $1 \%$ increase in accessibility of high speed railway lead to approximately $1 \%$ increase in GDP growth. Since the average annual accessibility rate increase from 2008 to 2014 is 0.88 , we multiply .88 by $\beta$ to obtain $.88 \%$. Over the $2008-14$, the marginal benefit of high speed railway accessibility improvement is:

$T M B_{H S R t}=(\beta \times A C C \%) \times \sum_{i=1}^{n} G D P_{i t}$,

where $\mathrm{TMB}_{\mathrm{HSR}}$ is the total marginal benefit of high speed railway of year $\mathrm{t}$. This implies HSR contributed to approximately 267 billion Yuan annually to the Chinese economy over the past five years (2010-2014). Since Chinese GDP average 53,638 billion, TMB ${ }_{\mathrm{HSR}}$ is equivalent to approximately .5\% of GDP. Overall, the net incremental benefits from HSR are approximately 240 billion Yuan annually, and over the past five years (2010-2014 period) represent 1.2 Trillion Chinese Yuan.

\footnotetext{
${ }^{7}$ Note, this also includes OLHSRt according to CRC's accounting standards and implies the actual costs maybe lower due to possible double counting. Our estimates hence of the total net benefit are then likely understated.

${ }^{8} \mathrm{Li}$ and Kuang (2011) estimate that most high speed railway lines in China generally can cover its incremental cost, but claim it's unclear whether they offset all HSR's fixed cost.
} 


\section{Out-of-Sample Monte Carlo Results}

Figures 3 and Table 10 present Monte Carlo simulations of the out-of-sample adjusted MSPE (Mean Squared Prediction Error), also known as the Clark-West statistic. Clark and West (2006) provide an adjustment to the difference in MSPE between two encompassing models that leads to increased power. The adjustment is the mean difference between the forecast error squared between two models $\left(\Sigma\left(\mathrm{Y}^{\mathrm{F}}{ }_{1}-\mathrm{Y}^{\mathrm{F}}{ }_{2}\right)^{2} / \mathrm{N}\right.$, where $\mathrm{Y}^{\mathrm{F}}{ }_{1}$ denotes the forecast of model one (the full model), and $\mathrm{Y}^{\mathrm{F}}$ the forecast of model two (the restricted model). It is added to the difference in squared forecast errors of models one and two: $\left(\Sigma\left(\mathrm{Y}^{\mathrm{A}}-\mathrm{Y}^{\mathrm{F}}\right)^{2} / \mathrm{N}\right)-\left(\Sigma\left(\mathrm{Y}-\mathrm{Y}_{2}\right)^{2} / \mathrm{N}\right)$, where the first (second) term is the MSPE for model one (two). Thus, the procedure takes the difference of the mean of the squared residuals, and then adds an adjustment to correct the nominal size, which then leads to higher power. The errors are then regressed against a constant, which as $\mathrm{T}$ gets larger, approaches a normal.

Our out-of-sample period in panel A has 402 observations, and Panel B 201 observations, and hence represents a relative large OOS period; however, unlike Clark and West's analysis, the large sample is driven by large $\mathrm{N}$, not large $\mathrm{T}$. Our results described below show that similar to other panel tests, such as the Levin and Lin or Im-Pesaran-Shin panel unit root tests, the power increases as the cross section increases.

Monte Carlo simulations of the adjusted MPSE illustrate the effect on the distribution of the errors as $\mathrm{N}$ gets larger. Figure 3 plots histograms of 10,000 adjusted MPSE with Clark-West statistic given by solid lines and normal critical values, given by solid bar lines; Table 10 reports associated mean, standard deviations and critical values. The histograms clearly illustrate that as $\mathrm{N}$ grows larger, the Clark-West critical values approach the normal critical values, given by solid bar lines. ${ }^{9} \quad$ Consider $\mathrm{N}=200, \mathrm{~N}=30$, the figure is enlarged to highlight that the critical values are very close to the normal distribution. Inspection of the $1 \%$ and $5 \%$ critical values are within $2-3 \%$ of the normal values for $(\mathrm{N}=200, \mathrm{~T}=30)$. Thus, our sample of $\mathrm{T}=30, \mathrm{~N}=200$ follows approximately a normal distribution. In contrast, for $\mathrm{T}=30(\mathrm{~N}=5)$, the $1 \%$ (5\%) critical values are $10-15 \%$ different than the C.V. of a normal distribution.

Table 10 further presents different combination of $\mathrm{N}$ and $\mathrm{T}$, and shows that as $\mathrm{N}$ increases, the standard deviations decline. For example, consider a $\mathrm{T}=30, \mathrm{~N}=1$, the standard deviation of the adjusted RMSE is 1.1; however, it declines rapidly when $\mathrm{N}$ increases. For $\mathrm{T}=30$ and $\mathrm{N}=5,10$, 30 and 200, standard deviations decline to $.48, .34$ and .20 and .08, respectively. Note, the standard deviation for $\mathrm{T}=5, \mathrm{~N}=30$ is .24 , and hence half of .48 , which occurs for $\mathrm{T}=30, \mathrm{~N}=5$. Additionally, there is little change in $\sigma$ for the last two columns, since when $\mathrm{N}$ is large, $\mathrm{T}$ does not have to be large; e.g., $\sigma$ is approximately the same .8 for $\mathrm{T}=5$ and $\mathrm{T}=30$. This is not true when $\mathrm{N}$ is smaller; e.g., $\mathrm{N}=5, \mathrm{~T}=5$, there is a large decline in $\sigma$ when you increase $\mathrm{T}$ to 30 . Overall, this means our sample of $\mathrm{T}=5$ and $\mathrm{N}=200$ is large; e.g., it is larger than a sample of $\mathrm{T}=100, \mathrm{~N}=1$, since Monte Carlo simulations, not shown for conciseness, show that $\sigma=.10$. Overall, the Monte Carlo simulations present convincing evidence of the importance of large $\mathrm{N}$ in reducing the standard errors of the adjusted MSPE and leading to a normal distribution.

\footnotetext{
9 The Appendix presents figures and additional tables for different $\square$ and $\square$ to highlight the robustness of the results; as the cross-section increases, the standard deviations rapidly decline.
} 
Finally, a problem with the simulations, similar to the panel unit root literature, is the presence of contemporaneous correlations which can cause potential size problems (see O'Connell, 1998; Strauss and Yigit, 2003). For our sample, however, the estimated correlation across the panel for the estimated OLS equations in Table 2, Column (1) used to generate the OOS in Table 8 average 14\%; thus, there is not substantial contemporaneous correlations. Since the $t$ statistics are well over four in Table 8 for testing whether ACC should be included, with an accompanying probability less than .001 ; it is unlikely that the presence of contemporaneous correlation will affect inference.

Lastly, Appendix III investigates the difference between railroads and road construction per capita on GDP per capita growth. Both the GMM and OLS estimates of ACC are similar to Tables 4 and 5, and support Granger causality from increases in ACC to higher growth in GDP per capita. In contrast, road construction does not have a positive effect on economic activity, the coefficient estimates tend to be insignificant or small negatives. Hence, the HSR results are robust to inclusion of road construction.

\section{Conclusion and Policy Advice}

This paper investigates the impact of high-speed railroads on city-level economic activity using a new dataset for approximately 200 cities in China from 2007-2014. We construct an accessibility metric that accounts for time savings and travel expenditures of Chinese high-speed railroads. The paper uses panel Granger Causality methods to highlight the impact of accessibility on economic activity. Results highlight that increases in accessibility significantly and substantially raise growth in GDP, GDP per capita and wages. Granger causality further is one-way from higher accessibility to increased economic activity. A cost benefit analysis additionally shows that the boost in GDP growth substantially outweighs the cost of high-speed rail construction.

Monte Carlo methods further validate the use of OLS to assess the importance of accessibility on economic growth as the parameter bias is relatively small. Simulations methods show that the adjusted mean squared prediction error can be used to evaluate the significance of the forecast errors in a panel with a large cross-section. Out-of-sample forecasts using OLS methods show that increases in high speed railroads significantly lower the forecast error and thus accessibility can predict out-of-sample GDP and GDP per capita growth. Accessibility explains an economically meaningful amount of the out-of-sample forecast variance of city-level GDP growth, further implying that the relatively large OLS parameter estimates are accurate. Lastly, the OLS parameter estimates are relatively stable and highlight that high speed railroads have not reached diminishing returns in recent years, and continue to spur positive regional activity. 


\section{References}

Anderson, T.W. and Hsiao, C. 1981. Estimation of dynamic models with error components. Journal of the American Statistical Association, 76, 589-606.

Arrelano, M., Bond S., 1991. Some tests of specification for panel data: Monte Carlo evidence and an application to employment equations. Review of Economic Studies 58, 277-297.

Arrelano, M., Bover, O, 1995. Another look at the instrumental variable estimation of error component models. Journal of Econometrics, 68, 1, 29-51.

Banister, D., Yossi, B., 2001. Transport investment and the promotion of economic growth . Journal of Transport Geography. 2001(9): 209-218.

Beck, N., Katz, J.N., 1995. "What to do (and What not to do) with Time-Series Cross-Section Data in Comparative Politics, American Political Science Review, 89 (3), 634-647.

Bian, Y., 2016. Rail Transit Incentive Subsidization Mechanism Design. China International Engineering Consulting Company.

Blum, U., Gercek, H., Viegas, J., 1992. High-speed railway and the European peripheries: opportunities and challenges . Transportation Research Part A. (26): 211-221.

Campbell, J. Y. and Thompson, S. B., 2008. Predicting excess stock returns out of sample: can anything beat the historical average?, The Review of Financial Studies 21(4), 1509-1531.

Chen, G., Silva, J., 2014. Estimating the provincial economic impacts of high-speed rail in Spain: an application of structural equation modeling . Social and Behavioral Sciences, 2014(111): 157-165.

Chen, C., Hall, P., 2012. The wider spatial-economic impacts of high-speed trains: a comparative case study of Manchester and Lille sub-regions . Journal of Transport Geography. (24): 89-110.

China Railway Corporation, 2015. Notice of China Railway Corporation on the Distribution of Fixed Asset Administrative Measures: 23.

China Railway Corporation, 2016. The 3rd Quarter Auditing Report: 3-5.

Clark, T.E., West, K., 2006. Using out-of-sample mean squared prediction errors to test the martingale difference hypothesis, Journal of Econometrics, 138, 291-311.

Coto-Millan, P., Inglada, V., 2007. Effects of Network Economics in High-speed Rail: The Spanish case. Annals of Regional Science, (41): 911-925.

Diebold, F. X., Mariano, R.S., 1995. Comparing predictive accuracy. Journal of Business and Statistics 13, 253-263.

Fang, W., Zhao, J., 2014. Dispersion of Agglomeration through High-speed Rail in China. Conference Paper. MIT urban planning. http://dusp.mit.edu/publication/dispersion-agglomeration-through-high-speed-rail-china.

Garmendia, M., Ribalaygua, C., Ureña, J.M., 2012. High speed rail: implication for cities. Cities. (29): S26-S31. 
Garrison, W.L., 1960. Connectivity of the interstate highway system . Paper and Proceedings of the Regional Science Association. (6): 121-137.

Glaeser E. L., Scheinkman, J. A., Shleifer, A., 1995. Economic Growth in A Cross-Section of Cities, NBER Working Paper. No. 5013.

Graham, D.J., 2007. Agglomeration, Productivity and Transport Investment. Journal of Transport Economics and Policy 41, 317-343.

Gutiérrez, J., 2001. Location, economic potential and daily accessibility: an analysis of the accessibility impact of the high-speed line Madrid-Barcelona-French border. Journal of Transport Geography 9, 229-242.

Gutiérrez, J., González, R., Gómez, G., 1996. The European high-speed train network: predicted effects on accessibility patterns . Journal of Transport Geography. (4): 227-238.

Hansen, W.G., 1959. How accessibility shapes land use . Journal of the American Institute of Planners. (25): 73-76.

Head, K., Mayer, T., 2000. Non-Europe: The magnitude and causes of market fragmentation in the EU. Weltwirtschaftliches Archiv, 136(2): 284-314.

Hensher, D.A., Truong, T.P., Mulley, C., \& Ellison, R., 2012. Assessing the wider economy impacts of transport infrastructure investment with an illustrative application to the North-West Rail Link project in Sydney, Australia. Journal of Transport Geography 24, 292-305.

Höchle, D., 2007. Robust Standard Errors for Panel Datasets with Cross-Sectional Dependence, Stata Journal, 7 281-312.

Hu, S., 2016. Study on the Effect of High Speed Railway on Agglomeration Economy of Cities along It. Beijing Jiaotong University.

Hu, Y., 2009. Study on Urban Growth, Effectiveness and Affecting Factors. Tianjin University.

Hsiao, C., 1986, Analysis of Panel Data, (New York: Cambridge University Press).

Jiao, J.J., Wang, J.E., Jin, F., Dunford, M., 2014. "Impacts on accessibility on China's present and future HSR network. Journal of Transport Geography, 40, 123-132.

Judson, R.A., Owen, A., 1999. Estimating dynamic panel data models: a guide for macroeconomists, Economic Letters, 65, 9-15.

Keeble, D., Owens, P. L., Thompson, C., 1981. Regional accessibility and economic potential in the European community . Regional Studies. (16): 419-432.

Kiviet, J.F., 1995. On bias, inconsistency and efficiency of various estimator in dynamic panel data models. Journal of Econometrics, 68, 53-97.

Levinson, D.M. (2012). Accessibility impacts of high-speed rail. Journal of Transport Geography 22, 288-291

Li, H.C., Kuang, X., 2011. HSR Profitability Analysis. Journal of Railway Economics Research, 4: 8-11. 
Li, S.M., Shum, Y. M., 2001. Impacts of the national trunk highway system on accessibility in China . Journal of Transport Geography. (9): 39-48.

Lin, S., 2011. “Urban Growth and Urban Development”. Urban Planning, 2011, 11: 11-18.

Liu, H. "Urban Growth, Land Appreciation and Urban Policies" . Journal of Central University of Finance and Economics, 2006, 08: 71-76.

Long, F., Wang, N., Zhang, Y., 2010. "Factors Affecting Urban Growth in China: Empirical Study on Cities at Prefecture Level and Above" . Urban Studies, (10): 83-86.

Minter, A., 2016. Just Say No to Chinese Railroads. Bloomberg. www.bloomberg.com/view/articles/2016-07-07/just-say-no-to-high-speed-rail

Morris, J.M., Dumble, P. L., Wigan, P. L. 1979. Accessibility indicators for transport planning. Transport Research Part A. (13): 91-109.

Murayama. Y., 1994. The impact of railways on accessibility in the Japanese urban system . Journal of Transport Geography. (2): 87-100.

Nickell, S., 1981. Biases in dynamic models with fixed effects. Econometrica 49, 1417-1426.

O’Connell, P., 1998. The overvaluation of purchasing power parity. Journal of International Economics 44, 1-19.

Ollivier, G., Bullock, R., Jin, Y., Zhou, N., 2014 “High-Speed Railways in China: A Look at Traffic, China Transport Topics, 11,. 93227.

Ortega. E., 2012. Territorial cohesion impacts of high-speed rail at different planning levels . Journal of Transport Geography, 2012(24): 130-141.

Poncet, S., 2003. Measuring Chinese Domestic and International Integration. China Economic Review, 14: 1-21.

Rapach, D., Strauss, J., Zhou, G., 2010. Out-of-sample equity premium prediction: combination forecasts and links to the real economy. The Review of Financial Studies, 23 (2), 821-862.

Rietvald, P., 1989. Infrastructure and regional development: A survey of multiregional models. The Annals of Regional Science., 23, 4, 255-274.

Rong C., 2014. On the fundamental Role of Spatiotemporal Economics in Economic Studies. Journal of Beijing Jiaotong University (Social Sciences), 2014 (10): 1-9.

Sasaki, K., Ohashi, T., Ando, A., 1997. High-speed rail transit impact on regional systems: does the Shinkansen contribute to dispersion. The Annals of Regional Science. (31): 77-98.

Shi, J., Zhou, N., 2013. How Cities Influenced by High Speed Rail Development: A Case Study in China . Journal of Transportation Technologies, 2013, 3: 7-16.

Strauss, J., Yigit, T., 2003. Shortfalls of panel unit root tests, Economics Letters, 81, 309-313

Sohn, J. Evaluating the significance of highway network links under the flood damage: an accessibility approach. Transportation Research Part A. 2006(40): 491-506. 
Ureña, J.M., Menerault, P., Garmendia, M., 2009. The high-speed rail challenge for big intermediate cities: A national, regional and local perspective . Cities. (26): 266-279.

Venables, A.J.,2007. Evaluating Urban Transport Improvements: Cost-Benefit Analysis in the Presence of Agglomeration and Income Taxation. Journal of Transport Economics and Policy 41, 173-188.

Vickerman, R., 1997. High-speed rail in Europe: experience and issues for future development. The Annual of Regional Science 31, 21-38.

Wang B., Rong, C., 2016. On the Spatiotemporal Significance of Enterprise Value. Journal of Beijing Jiaotong University (Social Sciences), (1): 11-31.

Wang H., Yuan Z., Hou, A., 2003. Review and Inspiration of Urban Growth Theories. Urban Planning Overseas, 03: 36-39.

Wang S., 2010. Study on the Development and Economic Influence of High Speed Railway in China. Journal of Southwest Jiaotong University, (5): 65-69.

Wang B., Rong, C.H., 2016. On the Spatiotemporal Significance of Enterprise Value. Journal of Beijing Jiaotong University (Social Sciences), (1): 11-31.

Wang, J., Jin, F., Mo, H., Wang, F., 2009. Spatiotemporal evolution of China's railway network in the 20th century: an accessibility approach . Transportation Research Part A. 2009(43): 765-778.

Willigers, J., Weem B, 2011. High-speed rail and office location choices. A stated choice experiment for the Netherlands . Journal of Transport Geography. 19: 745-754.

Wu, J., Li, H., 2016. Research on Railway Industry's Sustainability. National Development and Reform Commission.

Wu, J.H., 2013. "The Financial and Economic Assessment of China's High Speed Rail Investments: A Preliminary Analysis, International Transport Forum, Discussion Paper: 2013-28.

Wu, J., Nash, C., Wang, D., 2014. Is high speed rail an appropriate solution to China' rail capacity problems? . Journal of Transport Geography. (40): 100-111.

Young, A. The Razor's Edge: Distortions and Incremental Reform in the People's Republic of China . Quarterly Journal of Economics, 2000, (115): 1091-1135.

Yu, T., 2012. "Urban Growth in China: 2000 2010”. Urban and Regional Planning, 02: 62-79.

Young, A. 2000. The Razor's Edge: Distortions and Incremental Reform in the People's Republic of China . Quarterly Journal of Economics, (115): 1091-1135.

Zhang, H., 2011. Transmission Mechanism for the Effect of High Speed Railway on Narrowing Regional Gaps, China Transportation Review, (3): 49-50, 87.

Zhang X., Nie, Q., 2010. High-Speed Rail Construction and the Regional Economic Integration in China. Urban and Regional Development in High-speed Railway Era Modern Urban Research, (6): 7-10.

Zhao Y., 2011. Urban Growth Mode and Theory of Economics. Urban Planning Forum, 06: 12-19. 
Zhao J. Zhao Y.Y., Li Y., 2015. The variation in the value of travel-time savings and the dilemma of high-speed rail in China. Transportation Research Part A. (32): 130-140.

Zhou, G., Wang, X., "Factors Affecting Urban Growth in Yangtze Delta. Population Journal, 2014, 2(36): 36-44.

Zhou X., 2010. The Role of High Speed Railway in Promoting the Coordinated Development of Regional Economy. Railway Economics Research, (6): 19-22. 
Table 1 Monte Carlo Simulations

\begin{tabular}{|c|c|c|c|c|c|c|c|c|c|c|}
\hline \multicolumn{2}{|l|}{$T$} & 5 & 10 & 50 & 5 & 10 & 50 & 5 & 10 & 50 \\
\hline \multicolumn{2}{|l|}{$\mathbf{N}$} & 5 & 5 & 5 & 10 & 10 & 10 & 200 & 200 & 200 \\
\hline \multirow[t]{4}{*}{ OLS } & $\rho=.2$ & 0.435 & 0.447 & 0.454 & 0.496 & 0.494 & 0.504 & 0.571 & 0.571 & 0.571 \\
\hline & s.e. & 0.229 & 0.197 & 0.175 & 0.175 & 0.158 & 0.146 & 0.043 & 0.041 & 0.040 \\
\hline & $\beta=.8$ & 0.773 & 0.763 & 0.759 & 0.757 & 0.758 & 0.750 & 0.740 & 0.740 & 0.740 \\
\hline & s.e. & 0.255 & 0.175 & 0.079 & 0.179 & 0.124 & 0.058 & 0.039 & 0.029 & 0.014 \\
\hline \multirow[t]{4}{*}{ LSDV } & $\rho=.2$ & 0.035 & 0.121 & 0.184 & 0.041 & 0.124 & 0.185 & 0.048 & 0.127 & 0.186 \\
\hline & s.e. & 0.181 & 0.115 & 0.048 & 0.125 & 0.080 & 0.034 & 0.028 & 0.018 & 0.008 \\
\hline & $\beta=.8$ & 0.792 & 0.800 & 0.804 & 0.792 & 0.805 & 0.802 & 0.789 & 0.803 & 0.802 \\
\hline & s.e. & 0.249 & 0.156 & 0.062 & 0.169 & 0.109 & 0.045 & 0.037 & 0.023 & 0.010 \\
\hline \multirow[t]{4}{*}{ OLS } & $\rho=.8$ & 0.937 & 0.938 & 0.945 & 0.962 & 0.961 & 0.962 & 0.978 & 0.978 & 0.978 \\
\hline & s.e. & 0.092 & 0.069 & 0.047 & 0.045 & 0.036 & 0.027 & 0.007 & 0.005 & 0.004 \\
\hline & $\beta=.2$ & 0.199 & 0.199 & 0.195 & 0.194 & 0.196 & 0.193 & 0.192 & 0.191 & 0.192 \\
\hline & s.e. & 0.228 & 0.15 & 0.065 & 0.153 & 0.104 & 0.045 & 0.032 & 0.023 & 0.01 \\
\hline \multicolumn{2}{|c|}{ LSDV $\rho=.8$} & 0.353 & 0.566 & 0.757 & 0.371 & 0.579 & 0.76 & 0.388 & 0.592 & 0.763 \\
\hline \multicolumn{2}{|c|}{ s.e. } & 0.228 & 0.134 & 0.043 & 0.158 & 0.093 & 0.03 & 0.035 & 0.02 & 0.007 \\
\hline \multicolumn{2}{|c|}{$\beta=.2$} & 0.168 & 0.192 & 0.201 & 0.17 & 0.193 & 0.2 & 0.171 & 0.191 & 0.201 \\
\hline \multirow{5}{*}{ OLS } & s.e. & 0.236 & 0.152 & 0.064 & 0.16 & 0.108 & 0.045 & 0.034 & 0.024 & 0.01 \\
\hline & $\rho=.5$ & 0.575 & 0.587 & 0.612 & 0.619 & 0.626 & 0.636 & 0.668 & 0.668 & 0.668 \\
\hline & s.e. & 0.180 & 0.140 & 0.099 & 0.129 & 0.105 & 0.082 & 0.030 & 0.026 & 0.023 \\
\hline & $\beta=.5$ & 0.483 & 0.473 & 0.465 & 0.466 & 0.459 & 0.455 & 0.444 & 0.444 & 0.444 \\
\hline & s.e. & 0.219 & 0.148 & 0.068 & 0.149 & 0.103 & 0.050 & 0.032 & 0.023 & 0.012 \\
\hline \multicolumn{2}{|c|}{$\operatorname{LSDV} \rho=.5$} & 0.219 & 0.364 & 0.475 & 0.238 & 0.373 & 0.477 & 0.252 & 0.384 & 0.479 \\
\hline \multicolumn{2}{|c|}{ s.e. } & 0.206 & 0.124 & 0.047 & 0.141 & 0.086 & 0.034 & 0.031 & 0.019 & 0.008 \\
\hline \multicolumn{2}{|c|}{$\beta=.5$} & 0.509 & 0.519 & 0.508 & 0.507 & 0.516 & 0.507 & 0.502 & 0.517 & 0.506 \\
\hline & S.C. & 0.258 & 0.155 & 0.059 & 0.173 & 0.106 & 0.042 & 0.037 & 0.023 & 0.009 \\
\hline
\end{tabular}

The table presents 5000 Monte Carlo simulations for different $N, T, \rho$ (lagged autoregressive term) and $\beta$ (lagged distributed lagged term). We follow Kiviet (1995) with the simulation framework, and discard the first 50 simulations. The correlation between the $X$ and $Y$ terms is .25. Standard errors (s.e) are in the gray rows. 
Table 2 Granger Causality between GDP Growth and ACC - GMM Estimation

\begin{tabular}{|c|c|c|c|c|c|c|c|c|}
\hline \multirow{2}{*}{$\begin{array}{c}\text { PANEL A } \\
\text { GDP }\end{array}$} & \multicolumn{2}{|l|}{ DIFF } & \multicolumn{2}{|l|}{ ORTH } & \multicolumn{2}{|l|}{ DIFF1 } & \multicolumn{2}{|c|}{ DAGG } \\
\hline & Coeff & T stats & Coeff & T stats & Coeff & T stats & Coeff & T stats \\
\hline GDP(-1) & 0.24 & 4.70 & 0.22 & 3.83 & .27 & -2.64 & -0.53 & -2.75 \\
\hline GDP(-2) & 0.21 & 4.59 & 0.23 & 4.13 & .31 & -0.22 & -0.02 & -0.19 \\
\hline GDP(-3) & 0.19 & 3.76 & 0.19 & 3.62 & .26 & 0.89 & 0.05 & 0.79 \\
\hline $\operatorname{ACC}(-1)$ & -0.33 & -2.42 & -0.37 & -2.60 & -0.30 & 0.89 & 0.17 & 0.30 \\
\hline$A C C(-2)$ & 0.21 & 1.04 & 0.21 & 1.07 & 0.27 & 0.55 & 0.07 & 0.4 \\
\hline $\operatorname{ACC}(-3)$ & 1.28 & 9.74 & 1.30 & 9.71 & 1.04 & 4.53 & 0.28 & 2.42 \\
\hline IS(-1) & 0.20 & 4.75 & 0.17 & 4.12 & 2.81 & 2.76 & 0.21 & 3.33 \\
\hline IS-2) & -0.04 & -1.44 & -0.02 & -0.74 & 0.14 & 2.99 & 0.25 & 3.02 \\
\hline IS(-3) & 0.00 & 0.09 & 0.06 & 2.39 & -0.62 & 0.98 & 0.19 & 2.20 \\
\hline & Coeff & T stats & Coeff & T stats & Coeff & T stats & Coeff & $\mathrm{T}$ stats \\
\hline $\operatorname{GDP}(-1)$ & -0.21 & -9.99 & -0.16 & -11.35 & -0.04 & -2.21 & 0.11 & 1.99 \\
\hline GDP(-2) & 0.01 & 0.34 & 0.02 & 1.13 & 0.06 & 3.04 & -0.10 & -2.85 \\
\hline GDP(-3) & 0.03 & 2.26 & 0.04 & 2.51 & 0.04 & 3.22 & -0.01 & -1.21 \\
\hline$A C C(-1)$ & 0.30 & 7.69 & 0.35 & 11.85 & -0.11 & -4.16 & 0.58 & 4.08 \\
\hline$A C C(-2)$ & 0.15 & 2.64 & 0.10 & 2.07 & 0.37 & 2.76 & -0.10 & -1.51 \\
\hline$A C C(-3)$ & -0.29 & -10.19 & -0.34 & -17.11 & 0.24 & 8.45 & -0.18 & -4.51 \\
\hline IS(-1) & 0.06 & 3.17 & 0.04 & 3.49 & -0.03 & -1.68 & 0.00 & 0.16 \\
\hline IS-2) & -0.03 & -3.36 & -0.06 & -7.05 & 0.00 & 0.53 & -0.06 & -3.27 \\
\hline IS(-3) & 0.10 & 6.94 & 0.10 & 8.27 & 0.12 & 5.69 & -0.11 & -5.52 \\
\hline
\end{tabular}

Table 2 presents coefficient and $t$ statistics for different GMM specifications between GDP growth (GDP) and accessibility (ACC). The DIFF and ORTH reflects lagged differenced data (as in Arellano and Bond, 1991), and lagged Orthogonal Deviations (Arellano and Bover, 1995) and uses the AB-nstep. DIFF1 is an alternative specification that uses Arellano and Bond 1 step and also uses PCSE standard errors to assess an alternative error specification. DAGG subtracts cross-sectional means from each variable (which removes aggregate effects); it also uses the growth rate of accessibility to assess an alternative specification. IS represents industrial structure. 
Table 3 Granger Causality between GDP Growth and ACC, OLS Estimates

\begin{tabular}{|c|c|c|c|c|c|c|c|c|}
\hline \multirow{2}{*}{$\frac{\text { Panel A }}{\text { GDP }}$} & \multicolumn{2}{|l|}{ White } & \multicolumn{2}{|l|}{ PCSE } & \multicolumn{2}{|l|}{ LSDV } & \multicolumn{2}{|c|}{ LSDV DAGG } \\
\hline & Coeff & T stats & Coeff & T stats & Coeff & T stats & Coeff & T stats \\
\hline GDP(-1) & 0.10 & 1.31 & 0.10 & 0.67 & 0.04 & 0.66 & -.21 & -7.10 \\
\hline GDP(-2) & -0.06 & -1.76 & -0.06 & -0.56 & -0.11 & -1.95 & -0.11 & -4.63 \\
\hline GDP(-3) & -0.02 & -0.60 & -0.02 & -0.25 & 0.05 & 1.64 & -0.04 & -5.17 \\
\hline$A C C(-1)$ & -0.45 & -4.06 & -0.45 & -3.90 & -0.44 & -7.32 & 0.20 & 5.72 \\
\hline$A C C(-2)$ & 0.79 & 3.87 & 0.79 & 4.56 & 0.62 & 7.22 & 0.30 & 10.40 \\
\hline $\mathrm{ACC}(-3)$ & 0.75 & 4.77 & 0.75 & 2.93 & 0.72 & 4.01 & 0.35 & 8.23 \\
\hline IS(-1) & 0.09 & 3.45 & 0.09 & 3.85 & 0.10 & 6.40 & 0.13 & 7.86 \\
\hline IS-2) & -0.01 & -0.40 & -0.01 & -0.29 & 0.00 & -0.26 & 0.04 & 1.33 \\
\hline IS(-3) & 0.06 & 25.44 & 0.06 & 4.71 & 0.04 & 11.50 & 0.04 & 2.63 \\
\hline & Coeff & T stats & Coeff & T stats & Coeff & T stats & Coeff & $\mathrm{T}$ stats \\
\hline GDP(-1) & -0.05 & -2.30 & -0.05 & -2.58 & -0.07 & -3.21 & 0.01 & 1.13 \\
\hline GDP(-2) & -0.01 & -0.86 & -0.01 & -0.57 & -0.03 & -2.06 & -0.02 & -2.56 \\
\hline GDP(-3) & 0.00 & 0.00 & 0.00 & 0.00 & -0.01 & -0.65 & 0.01 & 2.82 \\
\hline$A C C(-1)$ & 0.43 & 2.03 & 0.43 & 1.79 & 0.32 & 1.33 & -0.03 & -3.45 \\
\hline $\mathrm{ACC}(-2)$ & -0.31 & -1.59 & -0.31 & -1.30 & -0.35 & -1.51 & 0.00 & -0.31 \\
\hline $\mathrm{ACC}(-3)$ & -0.27 & -2.38 & -0.27 & -1.48 & -0.27 & -1.59 & -0.03 & -3.42 \\
\hline IS(-1) & 0.00 & 0.23 & 0.00 & 0.32 & 0.00 & -0.17 & 0.01 & 1.06 \\
\hline IS-2) & 0.00 & -0.32 & 0.00 & -0.20 & 0.00 & 0.66 & 0.00 & -0.91 \\
\hline IS(-3) & -0.01 & -1.80 & -0.01 & -1.80 & -0.01 & -2.09 & 0.00 & -1.06 \\
\hline
\end{tabular}

Table 3 presents coefficient and t statistics for different OLS specifications between GDP growth (GDP) and accessibility (ACC). The first column uses a White heteroskedasticity correction that assumes the errors are contemporaneously or cross-sectionally correlated. PCSE is a panel corrected standard error procedure that accommodates arbitrary heteroskedasticity and within cross-section correlation (Beck and Katz, 1995). LSDV represents least squares dummy variables (or OLS with fixed effects). LSDV DAGG is an alternative specification that subtracts both cross sectional means from each variable and uses the growth rate of accessibility. IS represents industrial structure. 
Table 4 Granger Causality between GDP Per Capita and ACC, GMM Esimates

\begin{tabular}{|c|c|c|c|c|c|c|c|c|}
\hline & DIFF & & ORTH & & DIFF1 & & DAGG & \\
\hline GDP & Coeff & T stats & Coeff & T stats & Coeff & T stats & Coeff & T stats \\
\hline GDPPC(-1) & 0.25 & 4.12 & 0.31 & 1.03 & 0.39 & 0.22 & -0.35 & -2.32 \\
\hline GDPPC (-2) & 0.25 & 4.03 & 0.32 & 1.05 & -0.41 & 0.45 & -0.01 & -0.10 \\
\hline GDPPC (-3) & 0.13 & 2.43 & 0.19 & 0.98 & -0.16 & 0.24 & -0.04 & -0.78 \\
\hline$A C C(-1)$ & -0.64 & -4.75 & -0.64 & 1.01 & -0.55 & 0.51 & 2.29 & 3.19 \\
\hline$A C C(-2)$ & 0.48 & 2.05 & 0.62 & 0.94 & 0.60 & 0.87 & 0.16 & 0.41 \\
\hline$A C C(-3)$ & 1.08 & 8.43 & 1.14 & 9.62 & 1.09 & 4.81 & 0.09 & 0.37 \\
\hline IS(-1) & 0.18 & 4.08 & 0.18 & 1.37 & -0.15 & 0.24 & 0.11 & 1.37 \\
\hline (S-2) & -0.05 & -1.68 & -0.04 & 2.12 & 0.07 & 0.13 & 0.09 & 0.96 \\
\hline IS(-3) & 0.08 & 1.64 & -0.01 & -0.23 & -0.04 & 0.15 & 0.22 & 2.09 \\
\hline \multicolumn{9}{|l|}{ ACC } \\
\hline GDPPC (-1) & -0.22 & -9.98 & -0.16 & -9.34 & -0.07 & -0.07 & 0.03 & 0.37 \\
\hline GDPPC (-2) & -0.02 & -1.49 & 0.01 & 0.57 & 0.08 & 0.08 & -0.01 & -0.86 \\
\hline GDPPC (-3) & 0.01 & 1.28 & 0.02 & 1.85 & 0.05 & 0.05 & -0.01 & -1.09 \\
\hline$A C C(-1)$ & 0.28 & 7.79 & 0.34 & 12.34 & -0.11 & -0.11 & 0.07 & 0.26 \\
\hline$A C C(-2)$ & 0.05 & 0.81 & 0.04 & 0.75 & 0.33 & 0.33 & 0.02 & 0.48 \\
\hline$A C C(-3)$ & -0.30 & -10.70 & -0.35 & -16.42 & 0.22 & 0.22 & -0.05 & -1.45 \\
\hline IS(-1) & 0.04 & 2.94 & 0.03 & 2.34 & 0.00 & 0.00 & 0.02 & 0.61 \\
\hline IS-2) & -0.02 & -2.26 & -0.06 & -6.07 & 0.00 & 0.00 & -0.02 & -0.59 \\
\hline IS(-3) & 0.103 & 6.27 & 0.11 & 6.91 & 0.12 & 0.12 & -0.01 & -0.78 \\
\hline
\end{tabular}

Table 4 presents coefficient and $\mathrm{t}$ statistics for different GMM specifications between per capita GDP growth (GDPPC) and ACC. The DIFF and ORTH reflects lagged differenced data (as in Arellano and Bond, 1991), and lagged Orthogonal Deviations (Arellano and Bover, 1995). DIFFA is an alternative specification that uses Arellano and Bond 1 step and also uses PCSE standard errors. DAGG subtracts cross-sectional means from each variable; it also uses the growth rate of accessibility. IS represents industrial structure. 
Table 5 Granger Causality between Growth in GDP Per Capita and ACC, OLS Estimates

\begin{tabular}{|c|c|c|c|c|c|c|c|c|}
\hline Panel A & White & & PCSE & & LSDV & & & DAGG \\
\hline GDPPC & Coeff & T stats & Coeff & T stats & Coeff & T stats & Coeff & T stats \\
\hline GDPPC(-1) & 0.04 & 0.43 & 0.04 & 1.17 & 0.00 & 0.00 & -0.25 & -7.14 \\
\hline GDPPC(-2) & -0.07 & -2.34 & -0.07 & -2.22 & -0.12 & -2.10 & -0.24 & -9.19 \\
\hline GDPPC(-3) & -0.05 & -1.85 & -0.05 & -2.17 & 0.01 & 0.22 & -0.18 & -4.59 \\
\hline$A C C(-1)$ & -0.69 & -6.05 & -0.69 & -11.31 & -0.53 & -5.81 & 0.17 & 5.29 \\
\hline$A C C(-2)$ & 0.89 & 4.71 & 0.89 & 12.14 & 0.62 & 6.02 & 0.15 & 4.24 \\
\hline $\mathrm{ACC}(-3)$ & 0.75 & 5.05 & 0.75 & 9.85 & 0.63 & 3.15 & 0.18 & 4.80 \\
\hline IS(-1) & 0.08 & 2.91 & 0.08 & 4.75 & 0.09 & 3.35 & 0.09 & 4.95 \\
\hline IS-2) & 0.001 & 0.003 & 0.001 & 0.003 & -0.01 & -0.73 & 0.04 & 3.67 \\
\hline IS(-3) & 0.06 & 27.83 & 0.06 & 9.04 & 0.04 & 8.52 & 0.02 & 1.10 \\
\hline GDPPC(-1) & -0.05 & -2.47 & -0.05 & -2.64 & -0.06 & -3.17 & -0.11 & -3.87 \\
\hline GDPPC(-2) & -0.01 & -0.95 & -0.01 & -0.72 & -0.02 & -1.67 & -0.17 & -1.27 \\
\hline GDPPC(-3) & 0.00 & -0.03 & 0.00 & -0.03 & -0.01 & -0.42 & 0.48 & 2.79 \\
\hline$A C C(-1)$ & 0.43 & 1.99 & 0.43 & 1.77 & 0.34 & 1.38 & 0.33 & 0.82 \\
\hline $\mathrm{ACC}(-2)$ & -0.31 & -1.62 & -0.31 & -1.32 & -0.35 & -1.51 & 0.02 & 0.10 \\
\hline$A C C(-3)$ & -0.28 & -2.40 & -0.28 & -1.48 & -0.26 & -1.55 & -0.76 & -6.20 \\
\hline IS(-1) & 0.001 & 0.14 & 0.003 & 0.20 & 0.002 & 0.41 & -0.05 & -0.93 \\
\hline IS-2) & 0.001 & -0.30 & 0.004 & -0.18 & 0.001 & 0.02 & 0.13 & 1.84 \\
\hline IS $(-3)$ & -0.01 & -1.88 & -0.01 & -1.79 & -0.01 & -2.03 & -0.09 & -1.39 \\
\hline
\end{tabular}

Table 5 presents coefficient and $t$ statistics for different OLS specifications between per capita GDP growth (GDPPC) and ACC. The first column uses a White heteroskedasticity correction that assumes the errors are contemporaneously (cross-sectionally) correlated (period clustered). PCSE is a panel corrected standard error procedure that accommodates arbitrary heteroskedasticity and within cross-section correlation (Beck and Katz, 1995). LSDV represents least squares dummy variables. LSDV ALT is an alternative specification that uses growth rate of accessibility; DAGG subtracts cross-sectional means from each variable and uses the growth rate of accessibility. 
Table 6 Granger Causality between Wage Growth and ACC, GMM Estimates

\begin{tabular}{ccccccccc}
\hline & \multicolumn{1}{c}{ Diff } & \multicolumn{4}{c}{ Orthogonal } & \multicolumn{2}{c}{ RRDIF } & \multicolumn{2}{c}{ DAGG } \\
\hline WG & Coeff & T stats & Coeff & T stats & Coeff & T stats & Coeff & T stats \\
WG(-1) & 1.47 & 0.66 & -0.01 & -0.03 & -0.23 & -0.27 & -0.35 & -4.43 \\
WG(-2) & 2.51 & 0.83 & 0.16 & 0.65 & -1.19 & -2.27 & -0.18 & -4.71 \\
WG(-3) & 2.01 & 0.91 & 0.24 & 1.13 & -1.56 & -1.55 & 0.00 & -0.16 \\
\hline ACC(-1) & 1.18 & 0.44 & -0.20 & -0.58 & -0.04 & -0.04 & 1.61 & 5.69 \\
ACC(-2) & 3.50 & 0.38 & 2.20 & 0.79 & 0.04 & 0.06 & -0.19 & -1.15 \\
\hline ACC(-3) & 0.51 & 0.44 & 0.50 & 1.68 & 0.73 & 0.87 & 0.08 & 0.66 \\
\hline IS(-1) & 0.34 & 0.88 & 0.02 & 0.37 & -0.25 & -0.86 & -0.02 & -0.71 \\
IS-2) & 0.20 & 0.90 & 0.22 & 2.23 & -0.11 & -0.97 & 0.01 & 0.22 \\
IS(-3) & -0.55 & -0.97 & -0.33 & -2.47 & -0.01 & -0.08 & -0.01 & -0.46 \\
\hline
\end{tabular}

ACC

\begin{tabular}{|ccccccccc}
\hline WG(-1) & -0.06 & -0.52 & -0.01 & -0.12 & -0.02 & -0.16 & -0.01 & -0.17 \\
\hline WG(-2) & 0.00 & -0.05 & -0.02 & -0.33 & -0.03 & -0.28 & -0.02 & -0.56 \\
\hline WG(-3) & 0.00 & -0.07 & -0.01 & -0.31 & -0.04 & -0.35 & 0.00 & -0.28 \\
\hline ACC(-1) & 0.64 & 4.09 & 0.57 & 5.66 & -0.19 & -1.12 & 0.63 & 6.50 \\
\hline ACC(-2) & 3.85 & 3.13 & 2.76 & 3.44 & 0.49 & 3.20 & -0.24 & -2.44 \\
\hline ACC(-3) & -0.68 & -3.68 & -0.76 & -5.11 & 0.28 & 2.93 & -0.44 & -4.30 \\
\hline IS(-1) & 0.03 & 0.90 & 0.02 & 0.68 & -0.06 & -2.55 & 0.01 & 0.35 \\
\hline IS-2) & 0.00 & 0.08 & -0.07 & -1.99 & 0.01 & 0.32 & 0.01 & 0.59 \\
\hline IS(-3) & 0.07 & 1.38 & 0.15 & 4.18 & 0.11 & 3.74 & 0.00 & 0.02 \\
\hline
\end{tabular}

Table 6 presents coefficient and t statistics for different GMM specifications between wage growth (WG) and ACC. The DIFF and ORTH reflects lagged differenced data (as in Arellano and Bond, 1991), and lagged Orthogonal Deviations (Arellano and Bover, 1995). ALT is an alternative specification that uses growth rate of accessibility; DAGG subtracts cross-sectional means from each variable as well as also uses the growth rate of accessibility. IS represents industrial structure. 
Table 7 Granger Causality between Wage Growth and ACC, OLS Estimates

\begin{tabular}{|c|c|c|c|c|c|c|c|c|}
\hline Panel A & White & & PCSE & & LSDV & & LSD & DAGG \\
\hline Wage Growth & Coeff & T stats & Coeff & T stats & Coeff & T stats & Coeff & T stats \\
\hline WG(-1) & -0.01 & 2.23 & 0.04 & 1.39 & -0.32 & -1.87 & -0.18 & -5.58 \\
\hline WG(-2) & 0.16 & 3.01 & 0.05 & 1.75 & -0.21 & -9.11 & -0.12 & -3.67 \\
\hline WG(-3) & 0.24 & 2.21 & -0.07 & -4.03 & 0.00 & 0.98 & -0.03 & -0.97 \\
\hline$A C C(-1)$ & -0.20 & 2.66 & 0.02 & 0.46 & 0.21 & 1.45 & 0.40 & 6.03 \\
\hline$A C C(-2)$ & 2.20 & 9.11 & 0.43 & 6.21 & 0.06 & 0.73 & 0.25 & 10.91 \\
\hline$A C C(-3)$ & 0.50 & 1.17 & 0.43 & 7.79 & 0.15 & 2.12 & 0.23 & 8.06 \\
\hline IS(-1) & 0.02 & 0.38 & 0.03 & 2.64 & -0.03 & -101 & -0.02 & -.55 \\
\hline IS-2) & 0.22 & 0.23 & 0.02 & 1.97 & 0.03 & 1.32 & 0.02 & 1.19 \\
\hline IS(-3) & -0.33 & 0.57 & 0.02 & 3.14 & 0.01 & 1.47 & -0.01 & -1.91 \\
\hline WG(-1) & 0.00 & 0.31 & -0.01 & -1.48 & -0.32 & -8.82 & 0.01 & 0.66 \\
\hline WG(-2) & 0.00 & -0.35 & 0.00 & -0.05 & -0.22 & -6.32 & -0.02 & -1.85 \\
\hline WG(-3) & 0.00 & -1.81 & -0.01 & -2.43 & 0.00 & 0.61 & 0.01 & 1.22 \\
\hline$A C C(-1)$ & 0.46 & 21.42 & 0.43 & 16.60 & 0.02 & 2.11 & 0.13 & 1.09 \\
\hline $\mathrm{ACC}(-2)$ & -0.34 & -16.09 & -0.29 & -9.74 & 0.01 & 1.23 & 0.02 & 0.65 \\
\hline $\mathrm{ACC}(-3)$ & -0.41 & -10.40 & -0.30 & -12.17 & 0.02 & 2.17 & -0.09 & -3.02 \\
\hline IS(-1) & 0.01 & 1.46 & 0.00 & 0.27 & -0.03 & -1.47 & 0.01 & 2.98 \\
\hline IS-2) & -0.01 & -1.41 & -0.01 & -1.36 & 0.03 & 1.82 & 0.00 & -0.88 \\
\hline IS(-3) & 0.00 & -1.31 & -0.01 & -4.14 & 0.00 & 0.92 & -0.01 & -1.67 \\
\hline
\end{tabular}

Table 7 presents coefficient and t statistics for different OLS specifications between wage growth (WG) and ACC. The first column uses a White heteroskedasticity correction that assumes the errors are contemporaneously (cross-sectionally) correlated (period clustered). PCSE is a panel corrected standard error procedure that accommodates arbitrary heteroskedasticity and within cross-section correlation (Beck and Katz, 1995). LSDV represents a leas squares dummy variables that is an OLS procedure with fixed effects. LSDV ALT is an alternative specification that uses growth rate of accessibility; AGG subtracts cross-sectional means variable as well as also uses the growth rate of accessibility. 
Table 8 Out-of-sample OLS Forecasting Results for GDP and GDP per Capita Growth

\begin{tabular}{|c|c|c|c|c|c|c|c|c|}
\hline \multirow[t]{2}{*}{ 2013-2014 } & \multicolumn{3}{|c|}{ GDP } & \multicolumn{5}{|c|}{ GDPPC } \\
\hline & RMSPE & MAE & THEIL & BIAS & RMSPE & MAE & THEIL & BIAS \\
\hline BM & 0.172 & 0.141 & 0.937 & 0.371 & 0.177 & 0.147 & 0.492 & 0.332 \\
\hline IS, GDP, ACC & 0.150 & 0.109 & 0.802 & 0.197 & 0.159 & 0.136 & 0.500 & 0.238 \\
\hline IS, GDP & $0.157^{* * *}$ & 0.123 & 0.868 & 0.288 & 0.166 & 0.139 & 0.502 & 0.255 \\
\hline IS, ACC & $0.144 * * *$ & 0.097 & 0.738 & 0.114 & $0.144^{* * *}$ & 0.094 & 0.512 & 0.237 \\
\hline IS & 0.156 & 0.112 & 0.867 & 0.208 & $0.157 * * *$ & 0.095 & 0.494 & 0.059 \\
\hline GMM IS, GDP, ACC & 0.203 & 0.162 & 0.790 & 0.088 & 0.495 & 0.416 & 0.698 & 0.132 \\
\hline GMM IS, GDP,ACCF & $0.173 * * *$ & 0.131 & 0.834 & 0.124 & $0.158 * * *$ & .119 & 0.685 & .325 \\
\hline \multirow[t]{3}{*}{$\beta$ OLS/GMM } & -0.110 & -6.654 & & & -0.333 & -4.268 & & \\
\hline & 0.217 & 0.532 & & & 0.330 & 1.045 & & \\
\hline & 0.683 & 0.526 & & & 0.655 & 1.038 & & \\
\hline \multirow[t]{3}{*}{$\rho$ OLS/GMM } & -0.198 & -0.449 & & & -0.591 & 0.022 & & \\
\hline & -0.038 & 0.042 & & & -0.368 & 0.020 & & \\
\hline & 0.006 & 0.034 & & & -0.018 & 0.011 & & \\
\hline \multicolumn{9}{|l|}{2014} \\
\hline OLS & RMSPE & MAE & THEIL & BIAS & RMSPE & MAE & THEIL & BIAS \\
\hline BM & 0.186 & 0.149 & 0.968 & 0.299 & 0.212 & 0.157 & 0.539 & 0.249 \\
\hline IS, GDP, ACC & 0.159 & 0.105 & 0.684 & 0.098 & 0.178 & 0.095 & 0.569 & 0.026 \\
\hline IS, GDP & $0.172^{* * *}$ & 0.131 & 0.832 & 0.233 & 0.180 & 0.099 & 0.546 & 0.043 \\
\hline IS, ACC & $0.156 * * *$ & 0.095 & 0.642 & 0.042 & $0.171 * * *$ & 0.095 & 0.569 & 0.026 \\
\hline IS & 0.168 & 0.119 & 0.795 & 0.156 & 0.188 & 0.107 & 0.550 & 0.051 \\
\hline GMM IS, GDP, ACC & 0.222 & 0.184 & 0.685 & 0.459 & 0.463 & 0.342 & 0.695 & .012 \\
\hline GMM IS, GDP,ACCF & 0.154 & 0.107 & 0.597 & 0.103 & .179 & .114 & .507 & .008 \\
\hline \multirow[t]{3}{*}{$\beta$ OLS/GMM } & -1.162 & -4.191 & & & -0.380 & -4.272 & & \\
\hline & 0.443 & 0.903 & & & 0.477 & 1.067 & & \\
\hline & 0.638 & 0.985 & & & 0.621 & 1.054 & & \\
\hline \multirow[t]{3}{*}{$\rho$ OLS/GMM } & -0.157 & 0.136 & & & 0.192 & 0.025 & & \\
\hline & -0.109 & 0.149 & & & 0.003 & 0.026 & & \\
\hline & -0.042 & 0.031 & & & 0.174 & 0.015 & & \\
\hline
\end{tabular}

Root mean squared prediction error (RMSPE), mean absolute error (MAE), Theil (Theil) inequality coefficient and Bias are out-of-sample metrics for years 2013-2014 in the top panel and 2014 in the bottom panel. Rows 1 and 2 presents the OOS RMSPE forecast error for the benchmark constant (BM) and the full model using IS, ACC and GDP, respectively. Rows 3, 4 and 5 then drop variables to assess the change in OOS RMSPE. GMM procedure uses the Arrelano-Bond, N step procedure. $\beta \rho$ OLS/GMM presents the coefficient estimates for ACC (GDP) for OLS in column 1 and GMM in column 2 for GDP and columns 5 and 6 for GDP per capita. ACCF forecast uses the forecast from OLS, while GDP and IS is estimated with GMM. The $* * *$ is $1 \%$ significance and evaluates ACC inclusion/exclusion using the Clark West OOS MSPE. IS, GDP tests the exclusion of ACC relative to the full model above with all three variables; IS ACC tests the inclusion of ACC relative to the model below it with IS. Lastly, GMM, IS, GDP, ACCF tests the inclusion of the ACCF (the OLS forecast of ACC) relative to the row above it that does not include ACCF. 
Table 9 Total Incremental Cost Estimation for High Speed Railways (unit: 100 million Yuan)

\begin{tabular}{|c|c|c|c|c|c|c|c|}
\hline Year & \multirow[t]{2}{*}{2008} & \multirow[t]{2}{*}{2009} & \multirow[t]{2}{*}{2010} & \multirow[t]{2}{*}{2011} & \multirow[t]{2}{*}{2012} & \multirow[t]{2}{*}{2013} & \multirow[t]{2}{*}{2014} \\
\hline Item & & & & & & & \\
\hline $\begin{array}{l}\text { Profit after } \\
\text { Tax }\end{array}$ & -129.5 & 27.4 & 0.2 & 0.3 & 2.0 & 2.6 & 6.4 \\
\hline $\begin{array}{l}\text { Fixed Capital } \\
\text { Investment }\end{array}$ & 4168.0 & 7000.0 & 8235.0 & 4859.5 & 5480.6 & 5645.1 & 5902.6 \\
\hline Depreciation & 104.2 & 175.0 & 205.9 & 121.5 & 137.0 & 141.1 & 147.6 \\
\hline $\begin{array}{l}\text { Opportunity } \\
\text { Cost }\end{array}$ & 133.8 & 224.7 & 264.3 & 156.0 & 175.9 & 181.2 & 189.5 \\
\hline $\begin{array}{l}\text { Total } \\
\text { Incremental } \\
\text { Cost for } \\
\text { Railways }\end{array}$ & 367.5 & 372.3 & 470.1 & 277.2 & 311.0 & 319.8 & 330.7 \\
\hline $\begin{array}{l}\text { Total } \\
\text { Incremental } \\
\text { Cost for HSR }\end{array}$ & 257.3 & 260.6 & 329.1 & 194.0 & 217.7 & 223.8 & 231.5 \\
\hline Total GDP & 146863.8 & 193505.4 & 229096.6 & 272404.2 & 303795.6 & 337386.2 & 369796.7 \\
\hline $\begin{array}{c}\text { Total } \\
\text { Marginal } \\
\text { Benefit }\end{array}$ & 1298.49 & 1710.7 & 2025.4 & 2408.3 & 2685.8 & 2982.8 & 3269.3 \\
\hline
\end{tabular}


Figure 3 Monte Carlo Simulations for Adjusted RMSE $\rho=.2, \beta=.8$
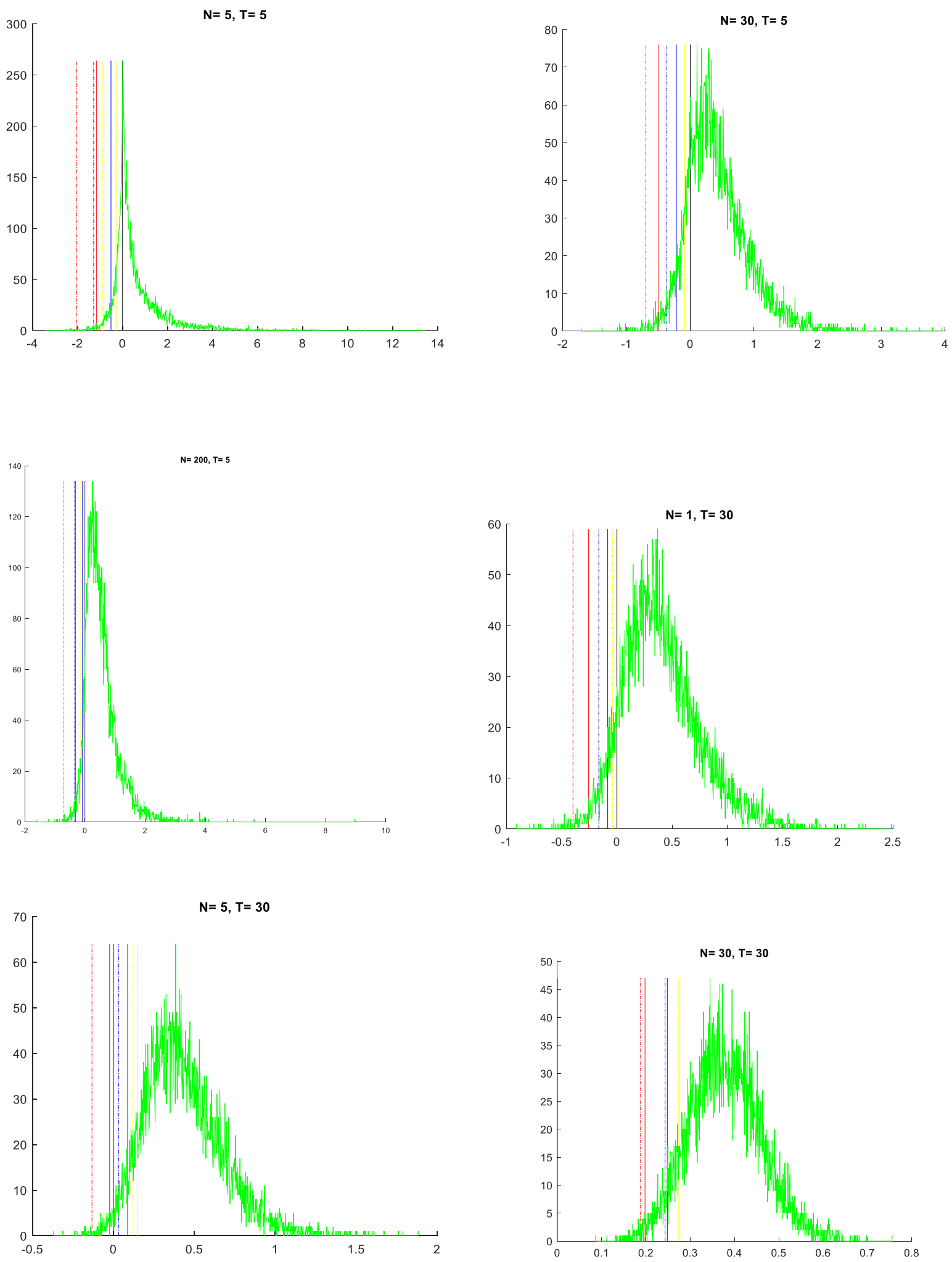


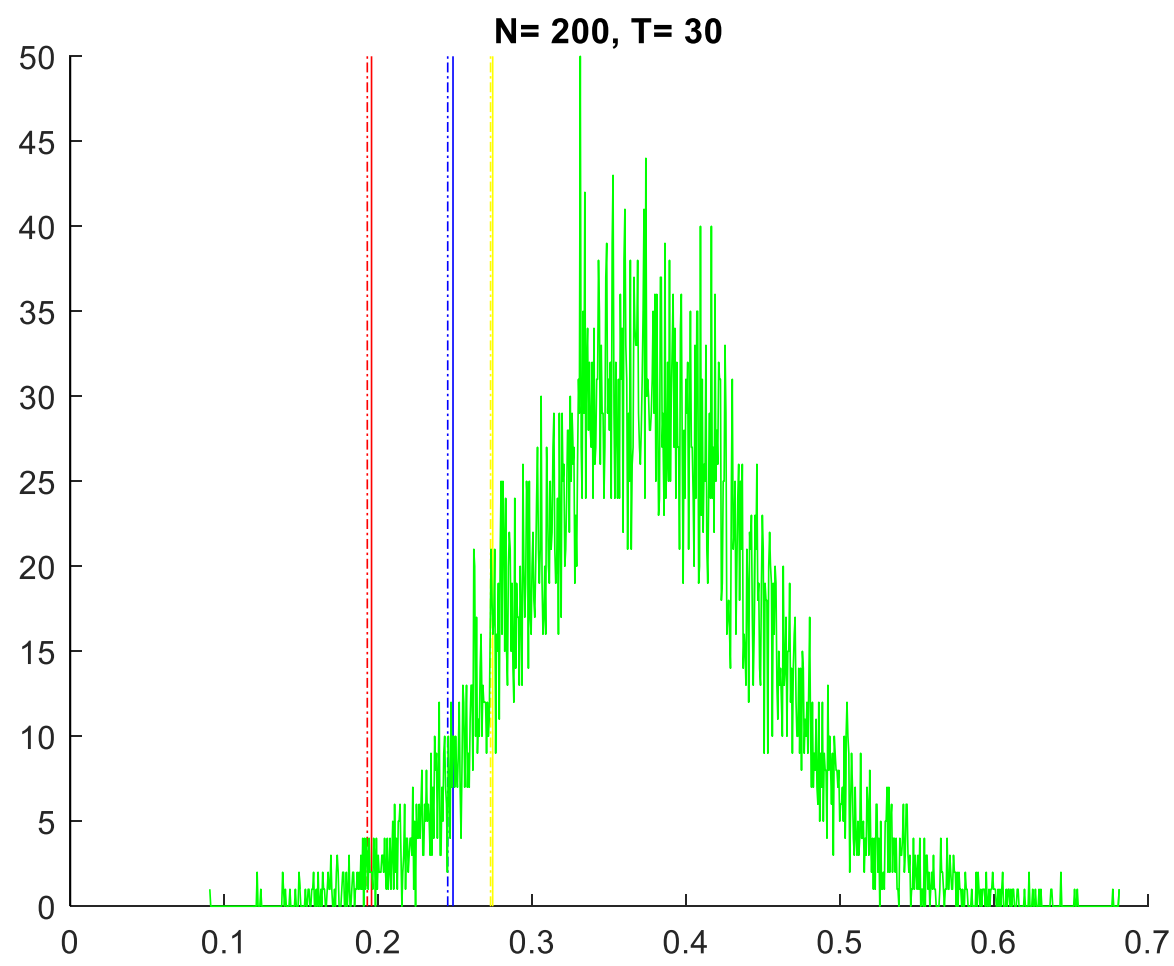

Dotted lines are the critical values for the simulation, and the solid lines are the normal.

\section{Table 10 Monte Carlo Simulations for Adjusted RMSE (Clark-West)}

$\begin{array}{lrrrrrrrrrr}\text { T } & 5 & 30 & 5 & 30 & 5 & 30 & 5 & 30 & 5 & 30 \\ \mathrm{~N} & 1 & 1 & 5 & 5 & 10 & 10 & 30 & 30 & 200 & 200 \\ \text { Mean } & -610885 & 0.53 & 0.70 & 0.42 & 0.52 & 0.40 & 0.43 & 0.38 & 0.38 & 0.37 \\ \text { St. Dev. } & 51580532 & 1.10 & 1.08 & 0.48 & 0.53 & 0.34 & 0.24 & 0.20 & 0.08 & 0.08 \\ & & & & & & & & & & \\ & & & & & \\ & -15081 & -1.15 & -0.77 & -0.49 & -0.32 & -0.26 & -0.02 & -0.03 & 0.20 & 0.20 \\ 5 \% \mathrm{CV} & -185 & -0.51 & -0.24 & -0.22 & -0.08 & -0.08 & 0.09 & 0.08 & 0.25 & 0.25 \\ 10 \% \mathrm{CV} & -24 & -0.29 & -0.09 & -0.09 & 0.01 & 0.01 & 0.15 & 0.14 & 0.27 & 0.27\end{array}$

